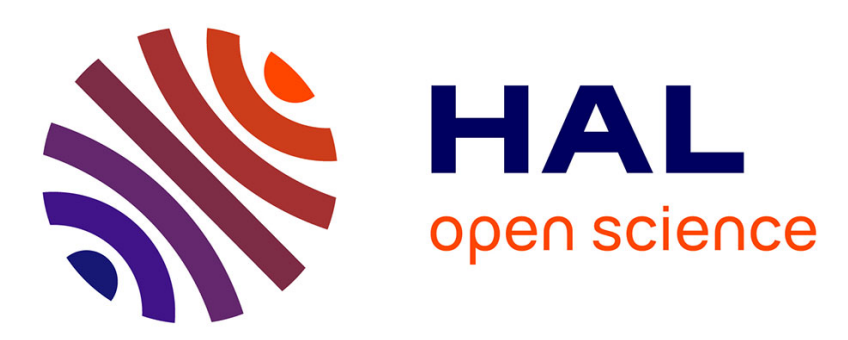

\title{
Analytical and numerical study based on experimental investigation of different curved sandwich composites manufactured by filament winding process
}

Mohamed Haddad, Laurent Guillaumat, Svetlana Terekhina, Mathilde Crozatier

\section{To cite this version:}

Mohamed Haddad, Laurent Guillaumat, Svetlana Terekhina, Mathilde Crozatier. Analytical and numerical study based on experimental investigation of different curved sandwich composites manufactured by filament winding process. Journal of Composite Materials, 2018, 52 (7), pp.891-917. hal-01785319

\section{HAL Id: hal-01785319 \\ https://hal.science/hal-01785319}

Submitted on 4 May 2018

HAL is a multi-disciplinary open access archive for the deposit and dissemination of scientific research documents, whether they are published or not. The documents may come from teaching and research institutions in France or abroad, or from public or private research centers.
L'archive ouverte pluridisciplinaire HAL, est destinée au dépôt et à la diffusion de documents scientifiques de niveau recherche, publiés ou non, émanant des établissements d'enseignement et de recherche français ou étrangers, des laboratoires publics ou privés. 


\title{
Analytical and numerical study based on experimental investigation of different curved sandwich composites manufactured by filament winding process
}

\author{
Mohamed Haddad, Laurent Guillaumat, Svetlana Terekhina \\ and Mathilde Crozatier
}

\begin{abstract}
Sandwich structures, due to their high stiffness versus lightness ratio, are used progressively in high performance products. In order to design these structures with the most appropriate dimensions and material combinations, relevant mechanical properties must be well understood. This work aims to estimate the elastic properties of composite sandwiches from a curved structure taking into account the manufacturing process. In the case of filament winding process, specimens are necessarily cylindrical or barrel extracted. In our case, these types of structures are tested in 3- and 4-point bending to analyze their behavior experimentally using predictive models and design rules. Different configurations are adopted for bending tests to analyze and discuss global mechanical behavior. Furthermore, the acoustic emission technique is used to detect the initial appearance of damage mechanisms and to examine their evolution in terms of amplitude peaks and localization. Finally, a correlation between these acoustic emission signals and the damage initiation mechanisms is proposed, considering their effects on the mechanical behavior of each tested material.
\end{abstract}

\section{Keywords}

Composite materials, curved sandwich structures, filament winding, experimental analysis, acoustic emission, damage mechanics

\section{Introduction}

Automotive companies have been driven to reduce weight while pushing performance boundaries. There is an increasing demand for lightweight and functional materials to enhance the properties of advanced composites. To achieve this goal, the adoption of this type of materials is an obvious choice. Knowing that they are generally designed to support bending forces, sandwich structures represent powerful materials for that and must meet other requirements such as corrosion, abrasion, fire resistance and thermal insulation. ${ }^{1-3}$ Basically, the choice of the type of sandwich depends on its application, like structures or structural parts requiring high stiffness and strength. When designed to be used in cylindrical structures like tanks, curved composite sandwiches are mostly subject to flexural and compressive loadings. These highly efficient multi- layered materials are designed to support radial and bending loads. They consist of a low-density core bonded between two thin and relatively rigid skins. ${ }^{4}$ The behavior of this type of structure constitutes the aim of the Huygens theorem: the resistance of a mechanically loaded section along a given axis varies with its quadratic moment along this axis. It should be noted that the geometry of a section is more significant than its corresponding mass. The high flexural performance is the major advantage of this type of multilayer material which requires additional

LAMPA - Laboratoire Angevin de Mécanique Procédés et innovAtion, Arts et Métiers ParisTech Campus Angers, France

\section{Corresponding author:}

Mohamed Haddad, Arts et Metiers ParisTech - Centre d'Angers, 2

Boulevard du Ronceray, Angers 49035, France.

Email: mohamed.haddad@ensam.eu 
information on its quasi static properties. The different polyethylene terephthalate- (PET), polyurethane- (PU) and polypropylene (PP)-based foams have numerous applications in diverse areas of engineering. ${ }^{3}$ In fact, a high structural strength with a low weight, an excellent fatigue resistance, and a very good temperature stability are the important factors that enable these materials to substitute more traditional core materials such as PVC or Balsa. ${ }^{5}$ For example, apart from the skins of sandwich structures which often do not allow that, the closed cell structure of PET foams ensures minimal humidity absorption and keeps the risk of physical degradation very low. ${ }^{6}$ Their ability to be recycled makes them very attractive for applications, focusing on "green aspects". With the basic properties of being a thermoplastic, PET foams have wide processing possibilities. Having both thermoset and thermoplastic properties allows this type of foam to be easily thermoformed, and thus tremendously extends the possibilities in design (3D-shape). Same as PET foams, PU- and PPbased foams are extremely low-weight hybrid core materials with mechanical properties that can be individually optimized. ${ }^{7}$ This offers a multitude of benefits for the production process.

Although many experimental and numerical works have been conducted on bending behavior of sandwich materials, they were limited to flat structures and not to curved ones. Several researchers have explored the failure modes of sandwich structures in flexure. ${ }^{8,9}$ Triantafillou and Gibson ${ }^{10}$ studied failure modes of sandwich beams with aluminum face sheets and a rigid PU foam core. Failure maps for various core densities and deflection ratios were constructed for face yielding, face wrinkling, core yield in shear, and core yield in tension and compression. Based on similar failure equations, a weight optimum design of composite sandwich structures was proposed by Yoshii. ${ }^{9}$ A summary of design approaches to sandwich construction is done by ZENKERT and may be found in Humer et al. ${ }^{11}$ while information on cellular solids is available in Shindo et al. ${ }^{12}$

In the present study, a description of materials manufacturing method was firstly made to give a general idea of the context. Next, a mechanical characterization was carried out on the sandwich curved specimens made by filament winding process with PET-, PU- and PPbased foams and glass-fiber/vinyl-ester composite laminated skins, focusing on flexural deformation mechanisms. The obtained composite was subjected to quasistatic flexural loading with full coupling of skin-core interaction to investigate its mechanical behavior. The main objective was to elucidate the deformation and failure damages regarding the different real specimens in parallel with an acoustic emission monitoring (AE) ${ }^{13,14}$ In addition, the experimental results have been compared with the classical beam theory to ascertain the reliability of the investigation findings. ${ }^{15,16}$

\section{Materials manufacturing}

Composites provide new solutions for manufacturers looking for stronger, lighter and more cost-effective materials. At the same time, they pose new modeling and manufacturing challenges due to curing, springback and residual stresses. To study the new curved structures, it was necessary to fabricate the different sandwich materials on a cylindrical mold having the dimensions of the final tank. These samples of sandwich materials presented in Table 1 were manufactured using the filament winding process, with the application of the real tension $(\sim 15 \mathrm{~N} /$ yarn $)$ on the glass fibers which form the two upper and lower skins, as shown in Figure 1(a) and (b).

The insertion of the light core material between the two facings allows an increase in thickness while limiting the increase in mass. Moreover, the positioning of the faces, which are often very rigid, as far as possible from the median plane, allows to maximize the quadratic moment and therefore the flexural rigidity. In some cases, functional properties are also desired such as energy absorption during shocks. Thus, the choice of the core material makes it possible to satisfy this type of multifunctional specifications, using in particular architectural materials (for example foams, trellises, embossed sheets). It is by considering these structural and functional specifications that the choice of constituent materials and geometric parameters should take place in an integrated approach.

Using the actual filament winding process on a mandrel with a diameter of $1500 \mathrm{~mm}$, our industrial partner was able to produce sandwich samples, using the selected candidate cores after a good research and study on the previously described materials. In fact, manufacturing has occurred in three phases:

1. Winding the first skin of the sandwich structure by depositing several layers of glass fibers to form $4 \mathrm{~mm}$ of thickness;

2. A manual putting in each type of sandwich core on the mandrel. For this step, a process design has been proposed to the company (described later), which facilitates the preparation task of the foams before their implementation into process (see Figure 3).

3. Winding of the outer skin (4 $\mathrm{mm}$ of thickness as well) and finish of the upper layer.

It was necessary to wait $2-3 \mathrm{~h}$ for the polymerization between each step. Finally, the extraction of the materials from the mandrel requires waiting at least $3 \mathrm{~h}$ after the end of the top skin. According to our industrial 
Table I. Description of different types of manufactured sandwich materials.

\begin{tabular}{|c|c|c|c|c|}
\hline Specimen type with: & $\begin{array}{l}\text { PET foam Gridded } \\
\text { Type }\end{array}$ & $\begin{array}{l}\text { PET foam Standard } \\
\text { Type }\end{array}$ & $\begin{array}{l}\text { PU foam with 3D glass } \\
\text { bridges }\end{array}$ & PP Honeycomb core \\
\hline Description & \multicolumn{2}{|c|}{$\begin{array}{l}\text { A rigid PET foam (polyethylene terephthalate) with } \\
\left.\text { different densities (70, } 100,150 \text { and } 200 \mathrm{~kg} / \mathrm{m}^{3}\right) \text {, } \\
\text { pre-cut as square grids (Grid) or Standard } \\
\text { (Ability to thermoform and easy to drape). This } \\
\text { solution also allows the manufacture of curved } \\
\text { shapes. It is compatible with all resins and } \\
\text { existing production methods. }\end{array}$} & $\begin{array}{l}\text { A hybrid material } \\
\text { which has a PU } \\
\text { foam based on a 3D } \\
\text { structure of glass } \\
\text { fibers stitched } \\
\text { transversely to } \\
\text { obtain optimized } \\
\text { mechanical } \\
\text { properties. }\end{array}$ & $\begin{array}{l}\text { A polypropylene } \\
\text { honeycomb used as } \\
\text { a core for sandwich } \\
\text { structural applica- } \\
\text { tions. It has been } \\
\text { specially designed to } \\
\text { facilitate the realiza- } \\
\text { tion of curved parts. }\end{array}$ \\
\hline \multicolumn{5}{|l|}{ Real structure } \\
\hline & 54 & & & \\
\hline
\end{tabular}

(a)

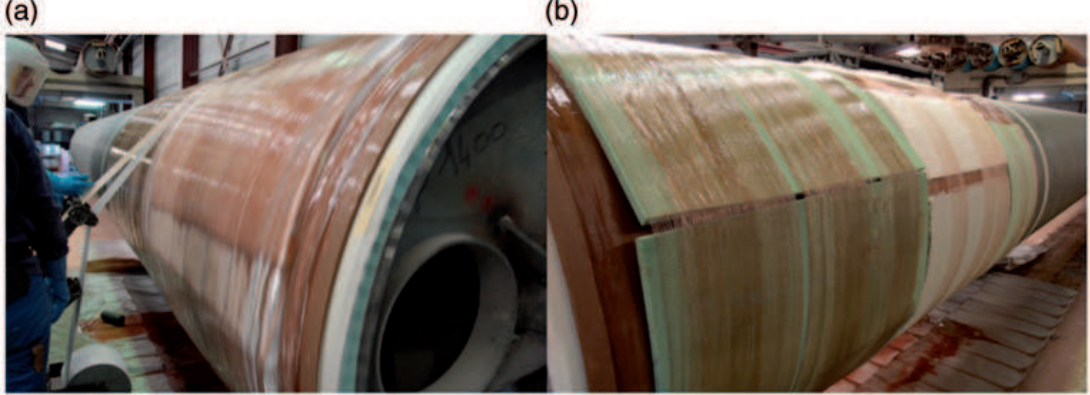

Figure I. Manufacturing of sandwich structures using filament winding process. (a) Lower skin and (b) upper skin.

partner, all types of foams were well wound because of their drapeability, and even the standard PET foam took the curved shape well.

It should be noted that PET foams (Gridded Type) and PP Honeycomb foams have a particular asset. As shown in Figure 2, grid sawn cores are often used for production of curved sandwich structures. The width of the sawed cuts is $1.5 \mathrm{~mm}$ for both materials. A thin net made of glass fiber is glued to the underside of the core. The nets function is to keep the blocks in place.

To continue with, the standard type of PET foams has many advantages as a sandwich core material. Compared to other candidate materials, it is easier to recycle, extremely resistant to variations in temperature, in addition to having excellent fatigue properties. Figure 3 presents a comparison of some mechanical characteristics of the various materials mentioned below, using a scale ranging from 1 to 6 in terms of shear, compressive and tensile relative strengths (MPa).

In order to carry out the manufacture of the sandwich structures by filament winding, a new process has

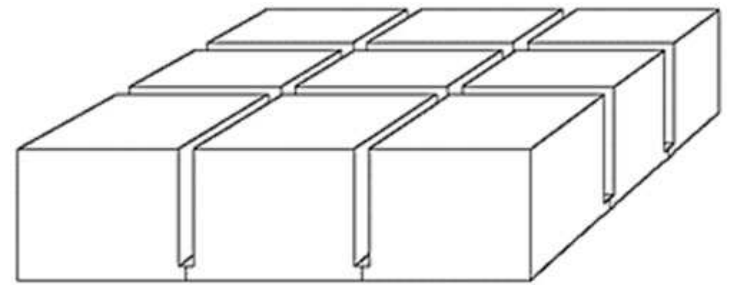

Figure 2. PET foams with grids for curved structures.

been designed which mainly concerns thermoformable standard PET cores. As shown in Figure 4, the foam block is shaped by heating the material to its softening point and forcing it against the surface of a male or female mold. It takes shape easily since it is a pure thermoplastic material with closed cells. It can be adapted even to double curved surfaces for different thicknesses. This solution seems to be relevant for use in filament winding; however, it requires an important and very specific tooling. 


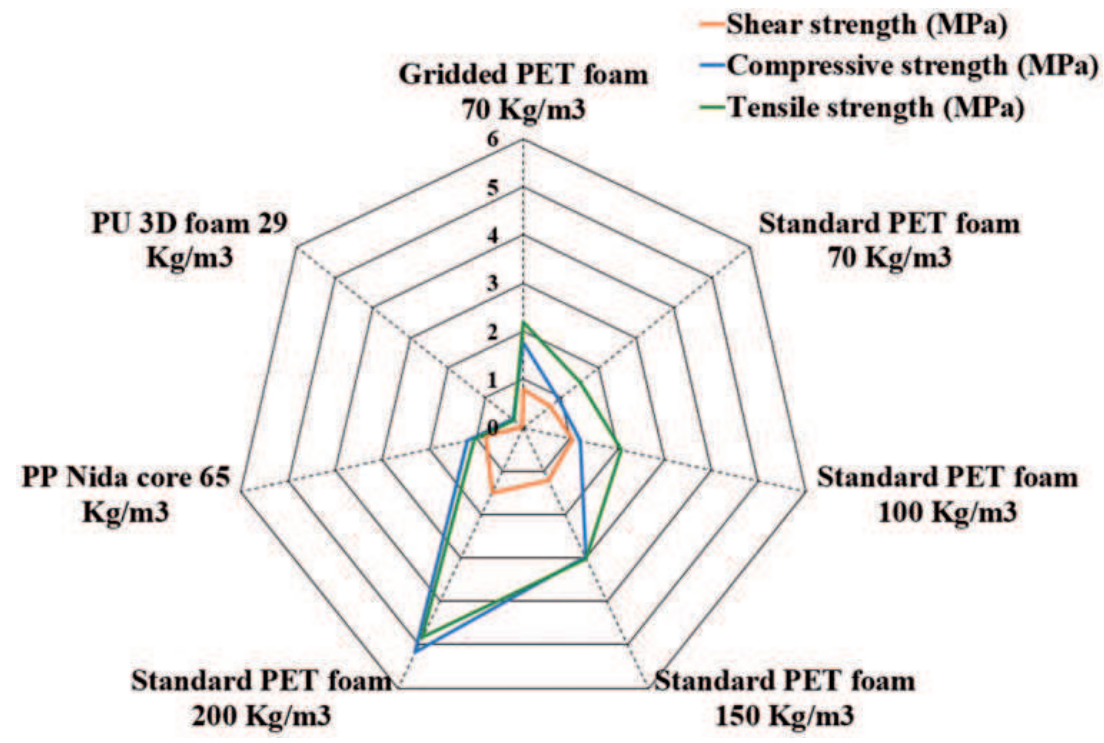

Figure 3. Comparison of the principal mechanical properties of PET, PU and PP sandwich cores (Supplier datasheets). ${ }^{6}$

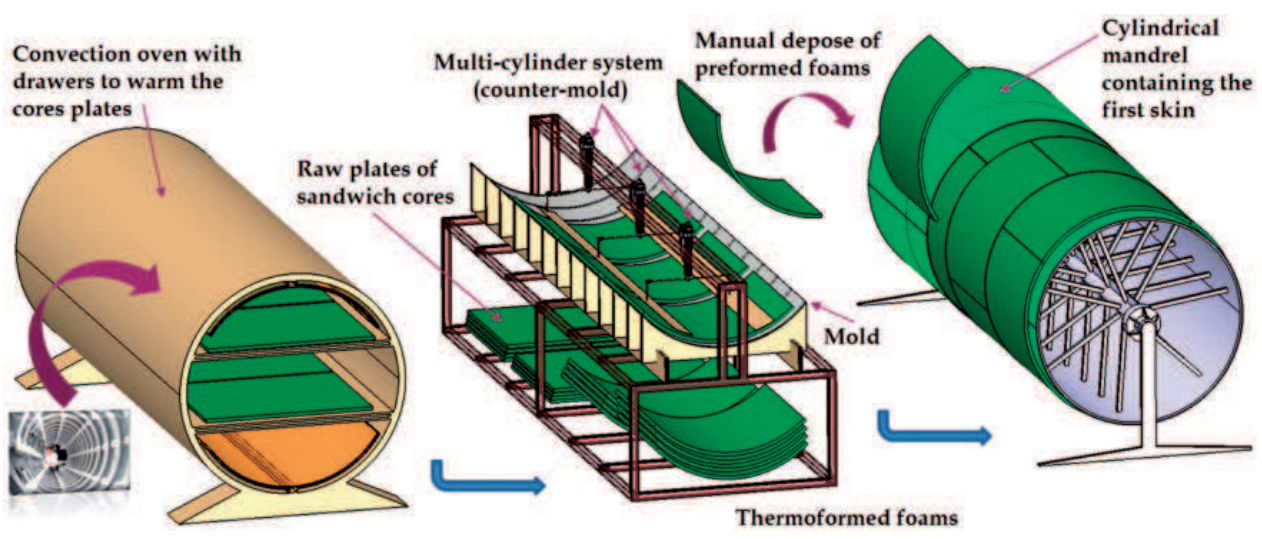

Figure 4. Proposed design of the thermoforming process (Standard PET foams).

Since the sandwich structure is used most often for its lightness, an important characteristic is the mass per unit area. Given the thickness of each facing " $e$ " "and the total thickness of the structure " $h$ ", this mass can be written as follows

$$
m_{s}=2 e_{p} \rho_{p}+\left(h-2 e_{p}\right) \rho_{a}
$$

with " $\rho_{p}$ " and " $\rho_{a}$ ", respectively, the density of the materials constituting the facing and the core. The relative thickness of the structure is defined as " $h / d$ ", where " $d$ " is a characteristic dimension of the test (Figure 5). This form relation is a very important one because it typically controls the choice of the predominant mode of deformation, whether in rigidity or resistance.

\section{Apparatus}

\section{Testing procedure}

A first batch of curved specimens is fabricated from a tank to represent the intended real structure. They were subjected to three- and four-point bending test to determine their overall stiffness and that of the different constituents in flexion and transverse shear. These configurations have the advantage of making the appearance of certain zones in pure bending ideal for the characterization of the predominant damage mode. After structural studies carried out by the partners of this project, it was decided that the skins constituting the structure should have several unidirectional plies of glass fibers placed in the two directions $0^{\circ}$ and $90^{\circ}$, with a total thickness of each skin $e_{p} \approx 4 \mathrm{~mm}$. The constituent core must have a thickness of $25 \mathrm{~mm}$ to form an 


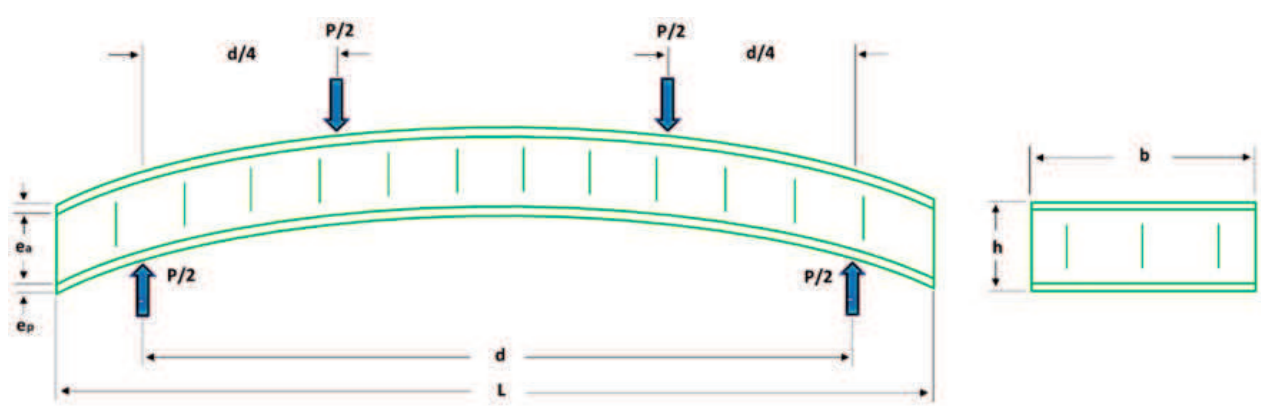

Figure 5. Schematic illustration of the bending test of sandwich structure with its characteristics.

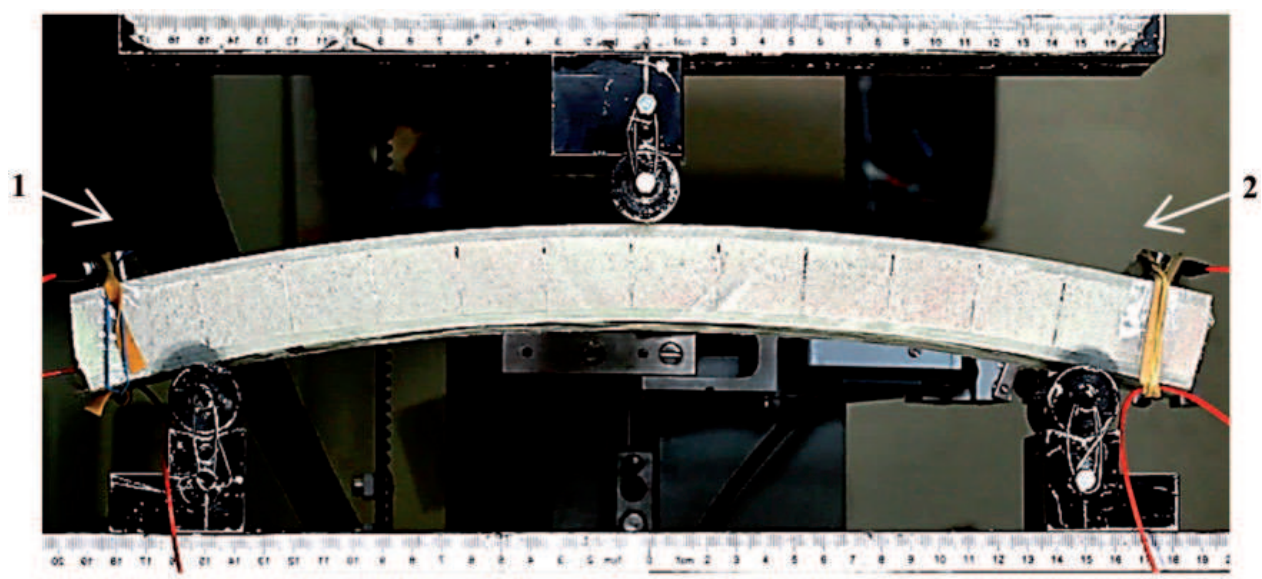

Figure 6. Sandwich specimen in experimental bending test with acoustic emission sensors (I) and (2).

overall thickness of the structure equal to $33 \mathrm{~mm}$. It should be recalled that all specimens were manufactured on a cylindrical mandrel with a curvature radius of $750 \mathrm{~mm}$ (Figure 1) as recommended by the industrial specification. To begin with, different types of sandwich core with variable densities between 29 and $200 \mathrm{~kg} / \mathrm{m}^{3}$ were used and chosen for their drapeability and their adaptability with our manufacturing method. In accordance with the standard, ${ }^{17}$ the length " $L$ " of tested samples is $400 \mathrm{~mm}$ for a width " $b$ " of $50 \mathrm{~mm}$ (Figure 5).

According to ASTM standards, ${ }^{17-19}$ each type of sandwich specimens was cut into required dimensions and tested for its quasi-static flexural properties by three and four-point bending test, on a properly calibrated testing machine from Zwick-Roell equipped with a $100 \mathrm{kN}$ force sensor. The test was operated in a displacement control mode with a constant crosshead speed of $5 \mathrm{~mm} / \mathrm{min}$, while the load output was recorded using a built-in load cell in the testing machine. The loading pins and the supports had a diameter of $25 \mathrm{~mm}$. To enrich our study, we highlight the correlations between acoustic signatures delivered by the two sensors placed on the specimens during mechanical testing (Figure 6), and the nature of the damage observed at the macrostructural scale and eventually the critical damage thresholds.

\section{$A E$ equipment}

The Acoustic Emission software AEwin ${ }^{\mathrm{TM}}$ from MISTRAS GROUP and a real-time data acquisition system were used for recording AE events. AE measurements are achieved by two piezoelectric sensors with a frequency range of $100 \mathrm{kHz}-1 \mathrm{MHz}$. The surface of each sensor was covered with grease in order to provide good acoustic coupling between the specimen and the sensor. The gain selector of each pre-amplifier was set to $50 \mathrm{~dB}$ (Figure 7). The amplitude of AE signals covers the range at $0-100 \mathrm{~dB}$.

Figure 8 shows a typical AE signal and the parameters commonly used for analysis. These are explained below:

- Threshold (in $\mathrm{dB}$ ): the threshold voltage level is generally set to distinguish signal from noise. An AE event or a part of it is counted only if the signal crosses the threshold level. 


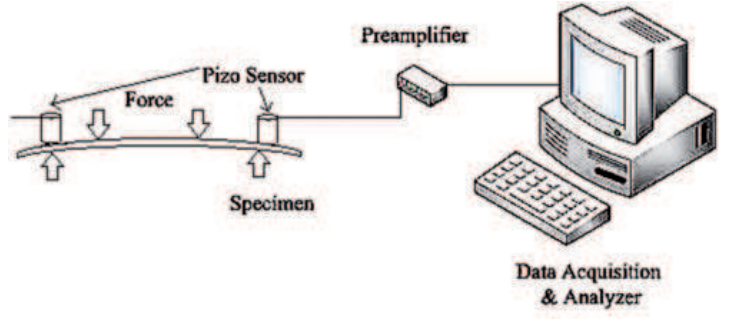

Figure 7. Device of control and characterization of material damage: Acoustic Emission.

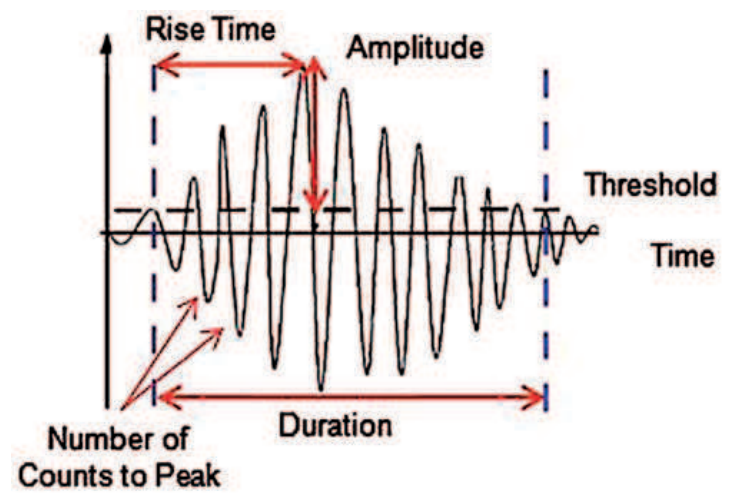

Figure 8. Common waveform parameters calculated by the acquisition system for each $A E$ event.

- Duration: is the time difference between the beginning of an event (marked when the signal crosses the threshold) and the end (marked when it falls below the threshold).

- Peak amplitude: highest amplitude attained by signal in an event which covers the range of $0-100 \mathrm{~dB}$.

- Counts: the number of times the signal crosses the threshold between the peak amplitude and the threshold.

- Rise time: time taken for signal to reach peak amplitude from the time it first crossed the threshold.

- Energy: the area under time versus amplitude squared curve for an event.

- Defect location: when more than one sensor is used, the AE source can be located and so will be the defective area. Location is based on the wave propagation principles within the materials and is effectuated by measuring the signal's arrival time to each sensor.

As shown in Figure 8, numerous parameters are calculated by the acquisition system for each AE event: amplitude, duration, rise time, counts, etc. Only the amplitude of the signal is measured in real time by the data acquisition system. All the other parameters are calculated from the waveforms and they are dependent on the amplitude threshold. Preliminary to damage check, the data acquisition system must be calibrated for each kind of specimens, according to a pencil lead break procedure (this procedure is explained in Shindo et al. ${ }^{20}$ ). Then, a repeatable acoustic wave is generated in the specimen by a lead breakage on its surface. At the same time, velocity and attenuation of the AE waves are measured. For that, the lead breakage operation was repeated several times and at different locations between the sensors. After the calibration step, AE signals are captured during mechanical testing. Signal descriptors such as amplitude, duration, rise time, counts, and defect location are then calculated by the AE software.

\section{Results and discussions}

\section{Mechanical behavior}

The main idea is to establish the mechanical flexural behavior and discriminate, in real time, the different types of damage and failure in the composite to understand the involved mechanisms that lead to the ruin of the structure. ${ }^{21,22}$ At the beginning of the test campaign, the response of the Zwick-Roell machine displacement sensor was compared with response acquired from LVDT sensor (see Figure 9(a) and (b)) to verify the possibility of using this method of measurement often unreliable in the case of assembly with low compliance.

As a conclusion from Figure 10, there is a good correlation with $\sim 2 \%$ of difference between slopes of the two curves, and therefore, the sensor following the displacement of the machine can be used in the bending tests of sandwich composites.

To properly compare the bending test results of the studied sandwich materials, the different curves have been normalized to their peak loads (Figure 11(a) and (b)). Total deflection $W(\mathrm{~mm})$ of all sandwich specimens is $30 \mathrm{~mm}$ in the case of three-point bending and $24 \mathrm{~mm}$ for the four-point bending. Thus, we observe evolutions of bending stress-strain relationships for the different types of sandwich structures presented in Table 1. The specimens were subject to three-point and four-point bending in order to observe the evolution of the stiffness of each material in accordance with the recommendations of the standards by Mathews and Swanson ${ }^{17}$ and Kalarikkal et al. ${ }^{23}$

A summary of the various experimental results for all types of specimens is presented in Table 2 (failure load, failure displacement and stiffness which is the slope of the linear part of force-displacement curve). The typical behavior of the tested specimens having different types of cores was quite similar for the threepoint or four-point test configurations. To explain this 
(a)

(b)

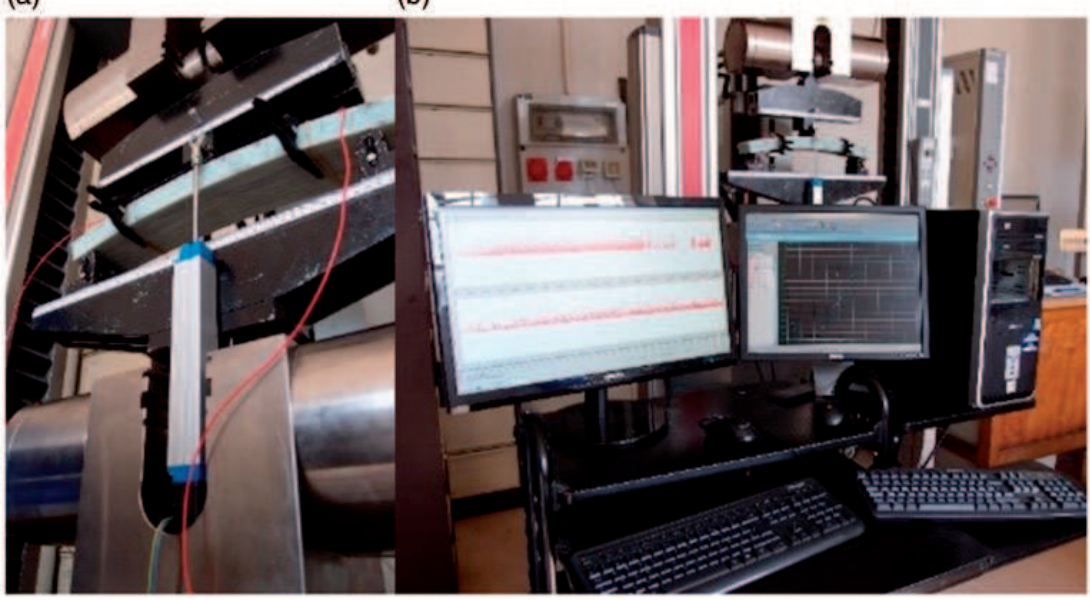

Figure 9. Equipment used for the acquisition of the comparison results between sensors: (a) LVDT and (b) machine sensor.

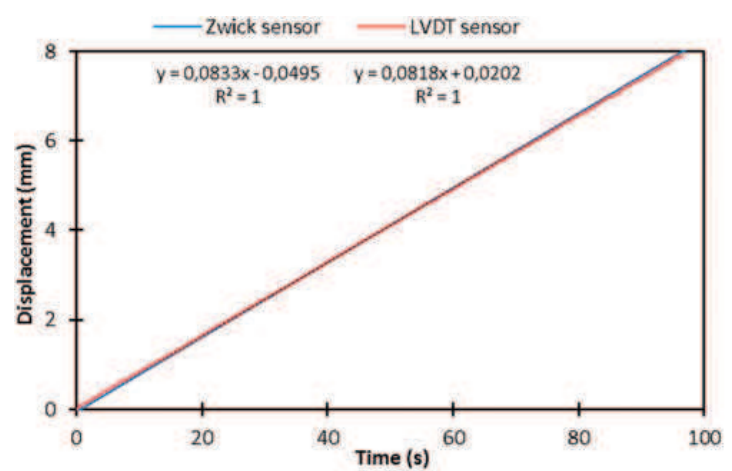

Figure 10. Comparison between the machine displacement sensor and LVDT sensor.

behavior, each stress-strain curve in Figure 11(a) and (b) is divided into three main zones. The first one represents the compressive behavior of skin laminate. This region corresponds to reversible linear behavior and the initiation of micro-cracking. The first part of this zone allows measuring stiffness in both three- and four-point bending tests. The second zone exhibits the compressive behavior of core due to the bending of the two skins and leads to non-linear behavior of stress-strain curve that is mostly dependent on the characteristics of core. In this zone, the load increases progressively until reaching the third zone of the curve which has the shape of a tray in which the load varies very slightly until the final failure of the specimen. Specimens with PU and PP foams which have a relative low density reaches the break after specimens with higher densities (with standard type of PET foams) while the specimens with gridded PET foams reach the break earlier than all other specimens, due to the presence of resin into grids shown at Figure 2. This will increase the overall stiffness of the structure since the resin forms 'bridges' between the two skins and this point is not to be neglected during the filament winding process.

So, compared to those with gridded PET foam type with a high presence of resin, the stiffness of the specimens with less resin into grids represents a decrease of $29 \%$ in three-point bending test, while an important decrease of $50 \%$ was observed in four-pt bending. The damage initiation begins near areas where there is a strong presence of resin. Also, the crack of the material is a consequence of that, as described in Figure 20.

\section{Theoretical and experimental evaluation of the flexural response}

Flexural stiffness and lightweight mass are the main reasons for the use of sandwich structures. However, pure bending stiffness is often not sufficient to quantify the performance of a structure since this solicitation never intervenes alone. Behavior in in-plane tension, out-of-plane compression, or transverse shear must not be neglected. In this section, we aim to express the characteristic properties of rigidity of the sandwich structure as a function of the material properties of the facings and the core. Two categories of properties are used depending on the context: the equivalent properties of the material and the macroscopic specimen properties. They are substitutable and easily deduced from each other considering the thickness of the structure. The equivalent properties of the material will tend more easily to the comparison and the selection of the materials. The properties of the specimen are more suitable for structural calculations.

Concerning our current experimental study, the ASTM test standard D7250 ${ }^{17}$ was used. Considering 
Sandwich with PET foam $70 \mathrm{Kg} / \mathrm{m}^{3}$ - Gridded ( + res) $h=33 \mathrm{~mm}$

Sandwich with PET foam $70 \mathrm{Kg} / \mathrm{m}^{3}$ - Gridded (- res) $h=33 \mathrm{~mm}$

Sandwich with PET foam $70 \mathrm{Kg} / \mathrm{m}^{3}$ - Standard $h=33 \mathrm{~mm}$

Sandwich with PET foam $100 \mathrm{Kg} / \mathrm{m}^{3}$ - Standard $h=33 \mathrm{~mm}$

Sandwich with PET foam $150 \mathrm{Kg} / \mathrm{m}^{3}$ - Standard $h=33 \mathrm{~mm}$

Sandwich with PET foam $200 \mathrm{Kg} / \mathrm{m}^{3}$ - Standard $h=33 \mathrm{~mm}$

Sandwich with Nida PP foam $65 \mathrm{Kg} / \mathrm{m}^{3} \mathrm{~h}=33 \mathrm{~mm}$

Sandwich with PU foam $29 \mathrm{Kg} / \mathrm{m}^{3}$ with $3 D$ bridges $h=33 \mathrm{~mm}$

Laminate composite skin $h=8 \mathrm{~mm}$

Laminate composite skin $h=22 \mathrm{~mm}$

(a)

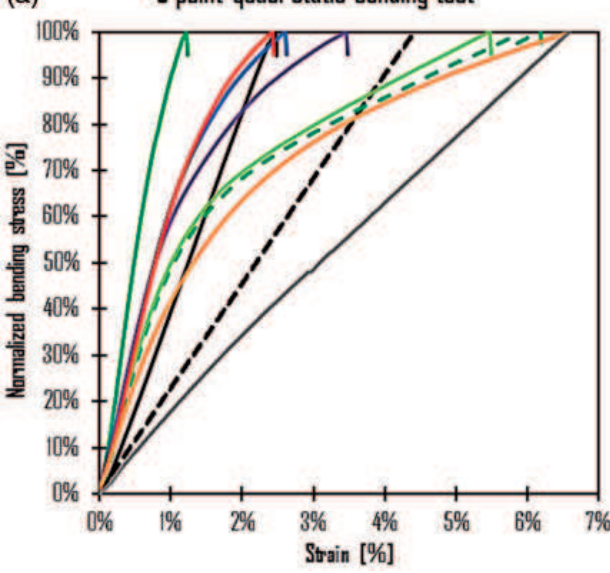

(b)

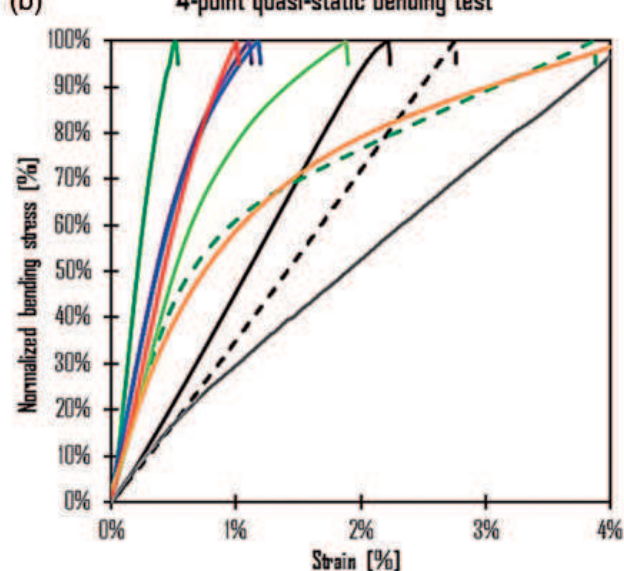

Figure II. Quasi-static flexural test results in 3 and 4-point bending: (a) and (b): normalized stress-strain relationship for specimens described above.

Table 2. Mechanical characteristics obtained in flexural static tests.

(I)

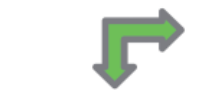

\section{Specimen type w
Bending test
Failure load $(\mathrm{kN})$
Failure displacem
$(\mathrm{mm})$
Stiffness $(\mathrm{N} / \mathrm{mm})$}

that equations (2) and (3) form a system of two equations with two unknown parameters, it is possible to use the results obtained by the three- and four-point bending test to solve this system. Thus, the equivalent rigidities are given below:

The flexural stiffness of the Sandwich structure $\left(N . m^{2}\right)$ is given by ${ }^{17}$

$$
D=\frac{P_{1} \mathrm{~d}_{1}^{3}\left(1-23 d_{2}^{2} / 18 \mathrm{~d}_{1}^{2}\right)}{48 W_{1}\left(1-3 P_{1} d_{1} W_{2} / 2 P_{2} d_{2} W_{1}\right)}
$$

The transverse shear rigidity of the sandwich structure $(N)$ is given by ${ }^{17}$

$$
N=\frac{P_{1} d_{1}\left(18 d_{1}^{2} / 23 \mathrm{~d}_{2}^{2}-1\right)}{4 W_{1}\left(27 P_{1} d_{1}^{3} W_{2} / 23 P_{2} d_{2}^{3} W_{1}\right)-1}
$$

where (for $i=1$ " 3 -pt bending" and for $i=2$ "4-pt bending") $P_{i}=$ total applied force $(\mathrm{N}) ; d_{i}=$ Support span length $(\mathrm{mm})$; and $W_{i}=$ beam mid-span deflection corresponding to force $P_{i}(\mathrm{~mm})$. 
The core shear modulus (MPa) can be deduced by ${ }^{17}$

$$
G=\frac{N\left(h-2 e_{p}\right)}{\left(h-2 e_{p}\right)^{2} b}
$$

where $h=$ sandwich thickness $(\mathrm{mm}) ; e_{p}=$ facing thickness $(\mathrm{mm})$; and $b=$ sandwich width $(\mathrm{mm})$.

On the other hand, and as explained at the beginning of this article, the theory of sandwich plates makes it possible to connect the characteristics of the constituents with the flexural rigidity. According to Lhuissier and Laszczyk, ${ }^{24}$ we can determine the flexural stiffness $\mathrm{D}$ and the transverse shear stiffness $\mathrm{N}$ of flat sandwich structures, while the shear modulus $G_{a}$ is given by the technical datasheets of the studied foams. Analytically, the transverse shear stiffness $(\mathrm{N})$ can be written as

$$
N=\frac{b h^{2} G_{a}}{e_{a}} \approx b h G_{a}
$$

where $e_{a}=$ core thickness $=h-2 e_{p}(\mathrm{~mm})$.

The first-order shear theory has been used to predict the flexural response of the sandwich structures assuming elastic linear response of all the constituents as well as full coupling constraints between the skin and the core. Using the measured elastic properties of each tested material, the expected failure mode could be specified as follow ${ }^{25-28}$ : compressive/tensile failure of the skin, shear failure of the core and compressive/ tensile failure of the core.

The in-plane failure (tension/compression) of the skin occurs when the applied load reached the ultimate strength of the skin material. ${ }^{29}$ It is expected that the failure of the sandwich structures will occur due to compressive failure of the top skin since the skins have higher tensile strength than the compressive strength. The failure of the sandwich specimen due to compressive failure of the skin is calculated by equating the moments within the sandwich specimen to the applied external bending moment. This gives a relation $^{30}$

$$
\sigma_{p}=\frac{M h}{2 E I} E_{p}
$$

where $\sigma_{p}(\mathrm{MPa})$ is the bending strength, $M$ is the moment about the neutral axis, $E$ is the tensile facing modulus, $E_{p}$ is the compressive modulus of elasticity of the skins and $I$ is the second moment of area about the neutral axis. So, the peak strength $P_{p}(\mathrm{~N})$ for this failure mode to occur can be predicted by equation (7).

$$
P_{p}=\frac{12 E I \sigma_{p}}{d E_{p} h}
$$

where EI is the flexural stiffness of the entire sandwich. This flexural stiffness can be obtained also using the sum of the flexural stiffness of the constituent parts about the centroidal axis of the composite sandwich section. The bending stiffness, EI $\left(\mathrm{N} . \mathrm{mm}^{2}\right)$ is calculated using equation (8).

$$
D=E I=\frac{b e_{p}^{3}}{6} E_{p}+\frac{b e_{p} h^{2}}{2} E_{p}+\frac{b e_{a}^{3}}{12} E_{a}
$$

where $E_{a}$ is the modulus of elasticity of the core.

The ultimate shear strength of the sandwich structure could be estimated since the shear stress is maximum at the centroidal axis and zero at the top and bottom surfaces. The shear stress $\tau(\mathrm{MPa})$ in a specimen can be determined using this relation ${ }^{31}$

$$
\tau=\frac{V Q}{I b}
$$

where $V$ is the transverse shear force at the considered section of the specimen and $Q$ is the first moment of area (section above area of interest). If there is experimentally a shear break of the core or of the core-skin bond under a maximum reached load $P$, the shear strength $\tau$ (MPa) can be calculated by

$$
\tau=\frac{P}{\left(h+e_{a}\right) b}
$$

Therefore, the peak load, $P_{a}(\mathrm{~N})$, for this kind of failure could be expressed by equation (11).

$$
P_{a}=\frac{2 \tau_{a} E I}{\left(E_{p} \frac{e_{p} h}{2}+E_{a} \frac{e_{a}^{2}}{8}\right)}
$$

where $\tau_{a}$ is the shear strength of the core material.

It is noteworthy that the ratio of the core/skin elastic modulus is much higher than the ratio of the core/skin shear modulus. Therefore, the transformed area of the sandwich cross section into an equivalent skin will be bigger than the transformed area using the ratio of the shear modulus. Thus, using the shear moduli ratio might better predict the shear capacity of the composite sandwich panels. The peak strength $P_{a p}(\mathrm{~N})$ for composite sandwich structures is predicted using equation (12). In this equation, GI is calculated similarly as equation (8) with the modulus of elasticity of the skin and the core replaced with its corresponding shear modulus.

$$
P_{a p}=\frac{2 \tau_{a} G I}{\left(G_{p} \frac{e_{p} h}{2}+G_{a} \frac{e_{a}^{2}}{8}\right)}
$$


where $G_{p}$ and $G_{a}$ are the shear modulus of the skin and the core, respectively.

The core material will fail if the normal stress in tension and/or compression exceeds the ultimate strength. The peak strength $P_{a s}(\mathrm{~N})$ for this failure mode can be predicted by equations (13) and (14).

$$
\begin{gathered}
P_{a s}=\frac{12 E I \sigma_{a t}}{d E_{a} e_{a}} \\
P_{a s}=\frac{12 E I \sigma_{a c}}{d E_{a} e_{a}}
\end{gathered}
$$

where $\sigma_{a t}$ at and $\sigma_{a c}$ are the maximum tensile and compressive strength of the core, respectively.

The classical shear theory ${ }^{32}$ was used to determine the load-deflection behavior of the composite sandwich structures, in which the total deflection is the sum of the bending and shear deflections. The relatively low shear stiffness of the core compared to that of the skin results in a significant shear deformation that should be accounted for in the total deflection of sandwich structures. ${ }^{33}$ Thus, the total deflection of the composite sandwich panels can be written as

$$
w_{\text {total }}=w_{b}+w_{s}
$$

where $w_{\text {total }}, w_{b}$ and $w_{s}$ denote the total deflection, deflection due to bending and shear, respectively.

For a simply supported beam under four-point static bending with an applied load $P$ and shear span $a$, the deflection at the mid-span of the beam due to unit and actual bending moments can be calculated by integrating the deflection from the support to the loading point $(0<x<a)$ and from the loading point to the mid-span $(\mathrm{a}<x<d / 2)$. This relation can be written as

$$
w_{b}=2\left[\int_{0}^{a}\left(\frac{M_{d}}{E I} \frac{x}{a}\right) \times\left(\frac{x}{2}\right) d x+\int_{a}^{d / 2}\left(\frac{M_{d}}{E I}\right) \times\left(\frac{x}{2}\right) d x\right]
$$

Simplifying equation (16) leads to equation (17)

$$
w_{b}=\left(\frac{M_{d}}{E I}\right)\left[\int_{0}^{a}\left(\frac{x^{2}}{a}\right) d x+\int_{a}^{\frac{L}{2}} x d x\right]
$$

By resolving this equation, it becomes

$$
w_{b}=\frac{23 P d^{3}}{1296 E I}
$$

For a simply supported beam, the shear displacement diagram is the same as the bending moment diagram, with a factor $k / A G$ applied to it, with $\mathrm{AG}$ often referred to as the shear stiffness of the sandwich beams $^{34}$ and $k$ is the shear correction factor. ${ }^{32}$ The maximum bending moment occurs at the mid-span of the beam. Consequently, the shear deformation at this location can be calculated as

$$
w_{s}=\frac{k}{2 G A}|P x|_{0}^{a}
$$

For the specimen, $a=d / 3$ while the shear correction factor $k=1.0$ is assumed in the analysis. The total deflection at the mid-span for the specimen can then be obtained by combining the equations (18) and (19).

This results in equation (20)

$$
w_{\text {total }}=\frac{23 P d^{3}}{1296 E I}+\frac{P d}{6 G A}
$$

The maximum elastic stress for each sandwich structure is given experimentally by the last value of the linear part of each curve, just before the beginning of initial damage. The experimental values corresponding to the detected elastic limit were then introduced into the numerical model and the value of the corresponding stress was deduced, taking into account the geometrical characteristics (curved form) of our test specimens. In parallel, another numerical model was also made with a plane structure in order to be able to compare the results of the two configurations and to deduce thereafter the effect of the curvature of the structures on the mechanical behavior of the studied sandwiches and to highlight the originality of the study carried out in this article. A comparison in terms of relative percentage has been incorporated into the curves to give relative and quantitative results.

For all types of materials, except structures with PET 70 Gridded foam, there is a good correlation $(1-3 \%)$ between the experimental and the numerical results relative to the maximum stress that corresponds to the maximum elastic load (Figure 12) and the flexural modulus (Figure 13) for each specimen. The results of the four-point bending tests properly show the flexural rigidity due to the configuration of the supports. In this way and by modeling the curved structure, there is a difference of $1.5 \%$ in average between the numerical and experimental values and a significant difference between the curved numerical model and the flat model, which is $\sim 8 \%$ on average. This initial stiffness difference could be reduced by using longer beams to reduce this effect, making it possible to increase the distance between supports to more than 20 times the thickness of the specimen in order to minimize the contribution of the specimen shape in relationship with the flexural stiffness. Therefore, having curved specimens will improve some mechanical characteristics of the structure with particularly a very important role of the residual stresses induced during the manufacturing process. 


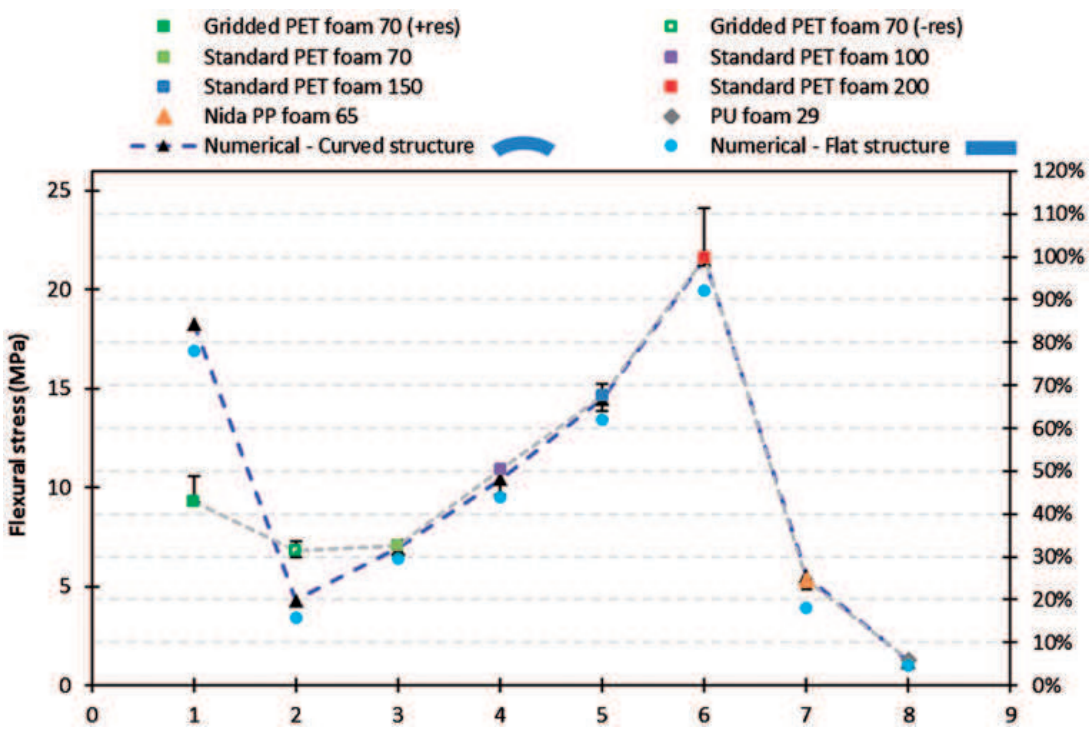

Figure 12. Maximum elastic stress for each studied structure.

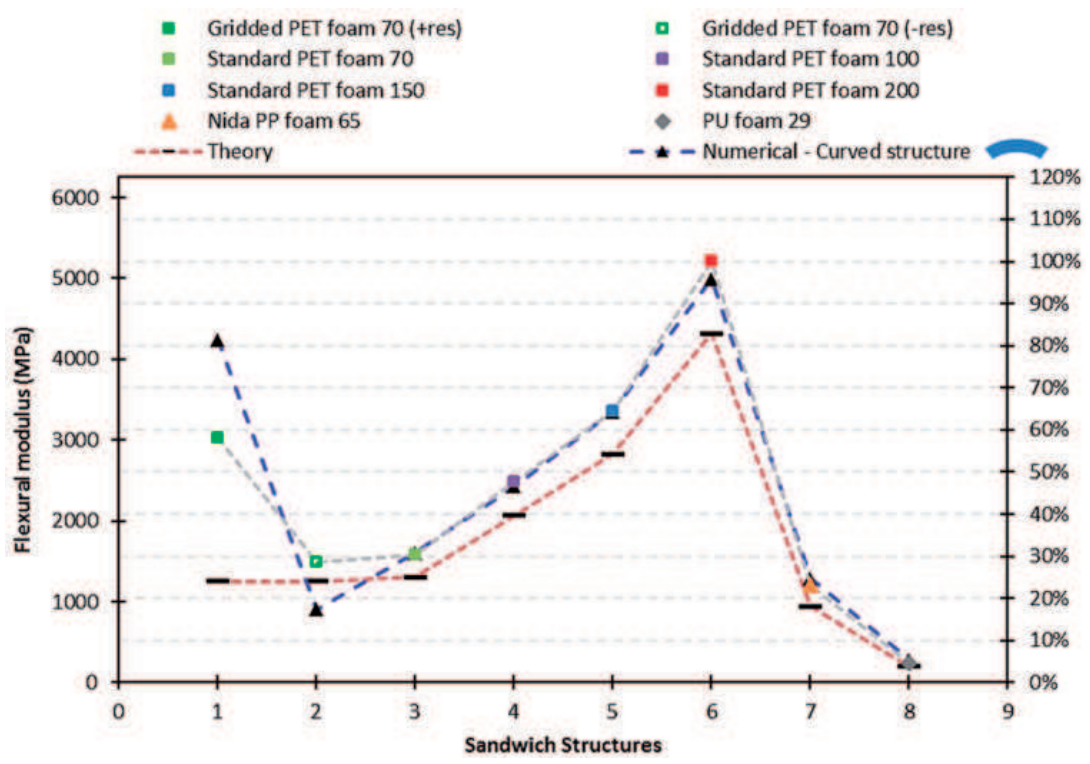

Figure 13. Flexural modulus for each studied structure.

The difference observed for both flexural stress and flexural elastic modulus for the two cases of structures with PET Gridded foam is explained by the fact that in the numerical models the resin content was $100 \%$ for the case of $(+$ Res $)$ and $0 \%$ in the grids for $(-$ Res). In reality, the estimated resin level is between $15 \%$ and $35 \%$ depending mainly on the method of winding of the gridded cores and the laying of the fibers already containing the resin, thus penetrating partially between the blocks forming the curved whole structure (Figure 14).
According to the standard by Kalarikkal et al. ${ }^{23}$ which relates to flat composite plates, it is possible to determine the flexural elastic modulus $E_{f}$ expressed in $\mathrm{MPa}$, using equation (21)

$$
E_{f}=\frac{0,21 d^{3}}{b h^{3}}\left(\frac{\Delta \text { load }}{\Delta \text { deflection }}\right)
$$

The flat plate theory seems to underestimate the flexural modulus of the sandwich structures with an average difference of $12 \%$ compared to the experimental 
(a)

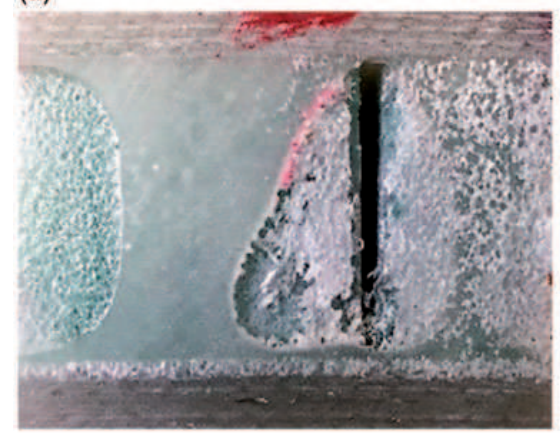

(b)

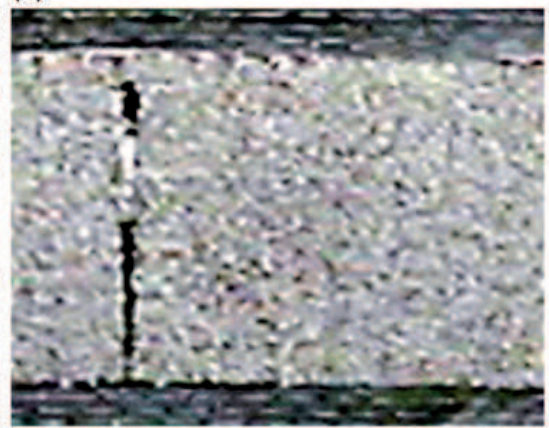

Figure 14. Sample view of a sandwich specimens with PET foam 70: (a) with more open grids (+ Res) and (b) with more closed grids (-Res).

Normalized bending stiffness of sandwich structures (N. $\mathrm{mm}^{2}$ )
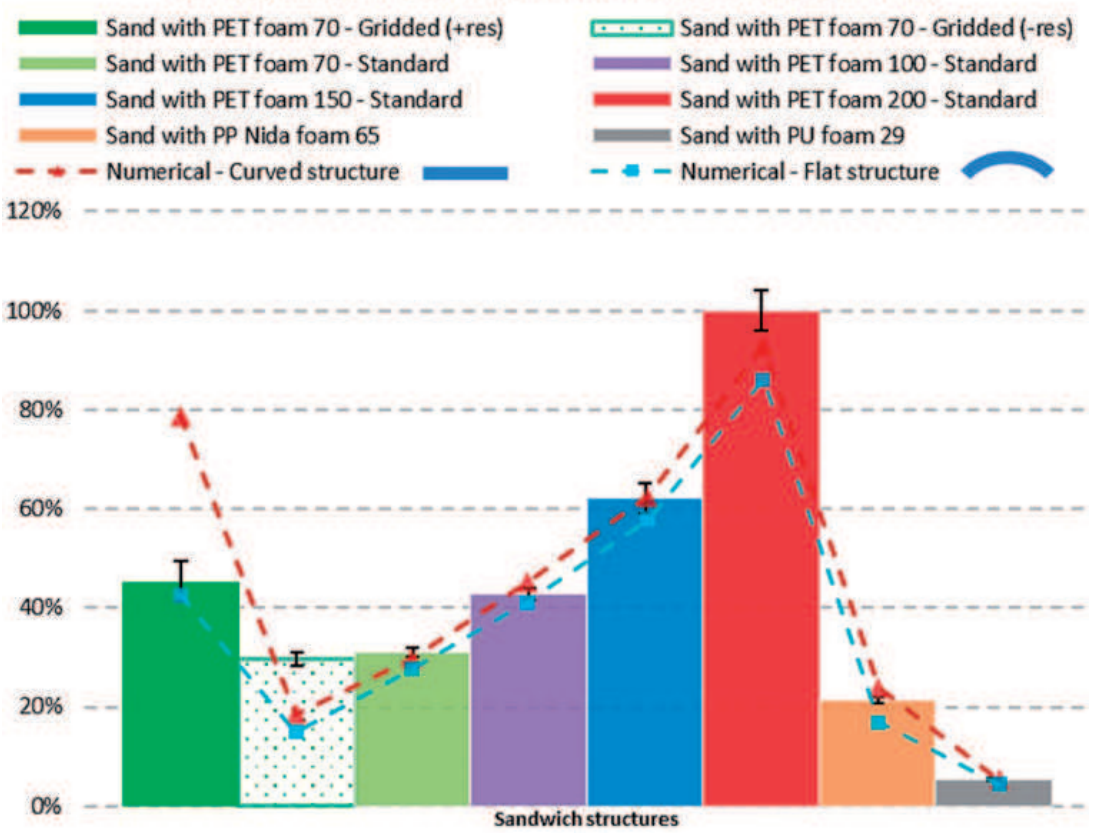

Figure I5. Normalized bending stiffness of studied sandwich structures with various densities.

results, as shown in Figure 13. In fact, this module increases with the relative density of the constituent cores since the overall stiffness of the structure also increases as a function of this material characteristic.

The comparisons of the stiffness calculations obtained for each type of sandwich material, as well as the analytical estimates and the numerical predictions in flexural tests, are given in Figures 15 and 16. So based on the results presented in the graphs below, we note that specimens with gridded PET foam type that include a high level of resin into grids show a high bending stiffness compared to other types that have the same foam density of $70 \mathrm{~kg} / \mathrm{m}^{3}$ into structure. This confirms that the importance of the presence of resin is not to be neglected; on the other hand, it has disadvantages such as the addition of the mass to the structure and therefore the overall weight of the tank. We also have a greater stiffness with a relative increased density for sandwich standard types without grids. Indeed, for this type of foam, the difference in bending stiffness regarding the structures with a standard core is $70 \%$ between those of $70 \mathrm{~kg} / \mathrm{m}^{3}$ and $200 \mathrm{~kg} / \mathrm{m}^{3}$. Also for the transverse shear stiffness, there is almost $65 \%$ of difference which is very significant. The importance of the density of the constituent foam for the same structural thickness is thus considered. It is worth noticing that the equations presented earlier have been established within the context of plane plates, which is not the case here. This confirms that the curvature also plays a fundamental role in the discrepancies observed 


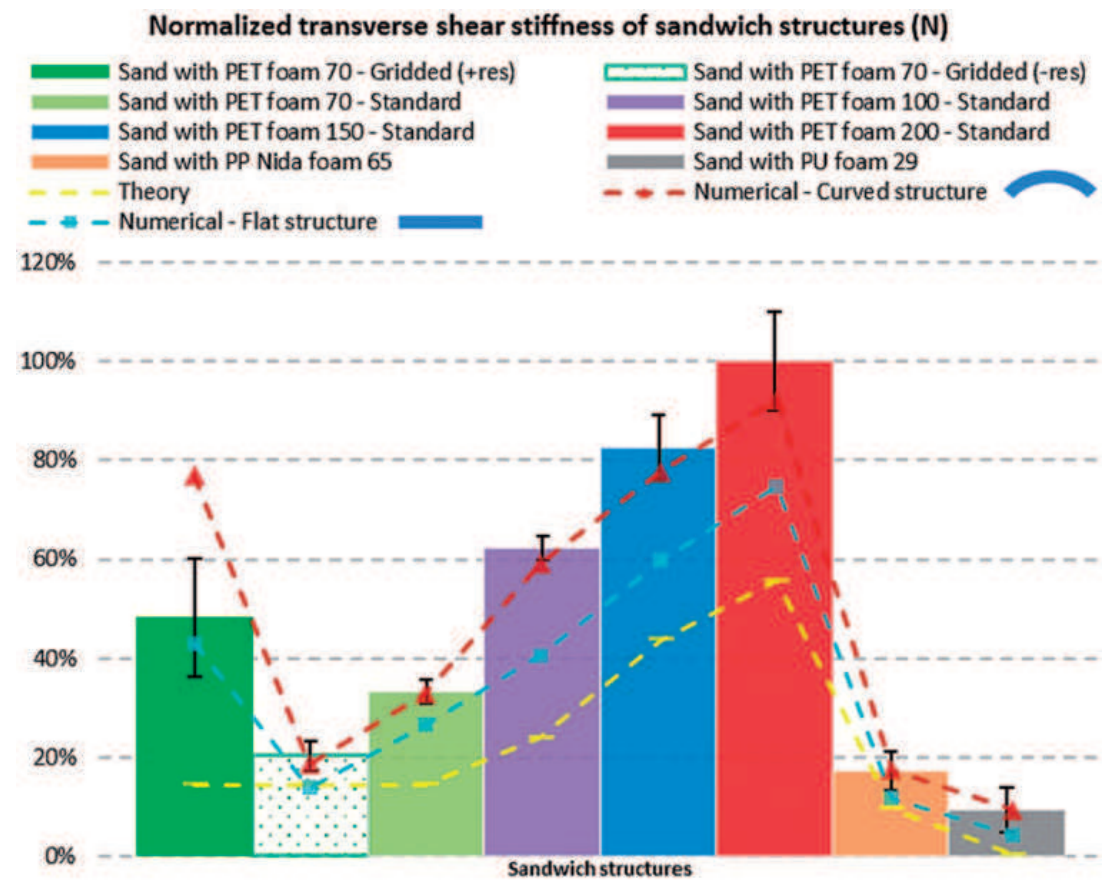

Figure 16. Normalized transverse shear stiffness of studied sandwich structures with various densities.

in responses and the behaviors of the studied structures, as we can see in Figures 15 and 16. It has a structural effect as expected. The different characteristic rigidities deduced from these results are very similar to those corresponding to the numerical modeling of each studied curved structure with an error valued between $2 \%$ and $5 \%$. These differences can be explained by: i) the local variations of the densities in each type of sandwich core, as well as by a possible stiffening of the foam due to the absorption of resin during the fabrication of the sandwiches by filament winding. ii) the parameters of the boundary conditions for the numerical model and iii) the mechanical properties of the different components, which can slightly change from one sample to another depending on the fiber ratio after winding, etc.

For sandwich structures with PU and PP foams, there is a large difference compared with other sandwiches, especially those with a core of $200 \mathrm{~kg} / \mathrm{m}^{3}$, due to the low compressive strength of these types of cores. Moreover, it should be noted that they have a major advantage which is the drape-ability and taking the curved shape with more flexibility.

To conclude, the failure load of the sandwich structure under flexural load depends mainly on the specimen geometry and the mechanical properties of the constituents. Among the most important properties of a core which constitute a real criterion of choice, are its shear resistance and its flexural modulus. Furthermore, especially when thin skins are used, the core must be able to support the compressive loading without premature failure, in order to avoid buckling damage of the skins following their wrinkling initiation.

\section{Predicted results and discussion}

The results of the theoretical prediction and numerical simulations of the flexural behavior of the composite sandwich specimens and comparison with the experimental results are discussed in the following section. The normalized stress-strain curves, presented previously in Figure 11(a) and (b), show firstly a quasi-linear behavior of the specimens up to significantly high loads, then a nonlinear behavior up to a maximum load due to initial structural damages occurring roughly. Primarily, the core reaches its elastic limit when the shear load increases. This maximum shear load is significantly lower for bending tests with fourpoint loading configuration having a certain load span length (distance between the upper load supports). The reason for this finding is that, for this type of test, the rigidity of sandwich materials is affected by the sharp decrease in shear effort. So, for every studied sandwich material, the limit of the elastic behavior is reached essentially when the foam reaches its elastic shear limit. Under these conditions, the materials will be solicited by transverse shear stresses. We observed common cases of shear failure of the core or delamination of core/skin interfaces. The variability of density of the core constituent regarding PET standard structures leads to the modification of the elastic limit and 


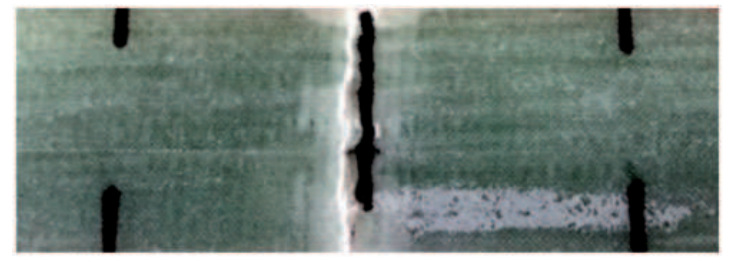

Figure 17. Localized cracking on the upper skin.

(a)

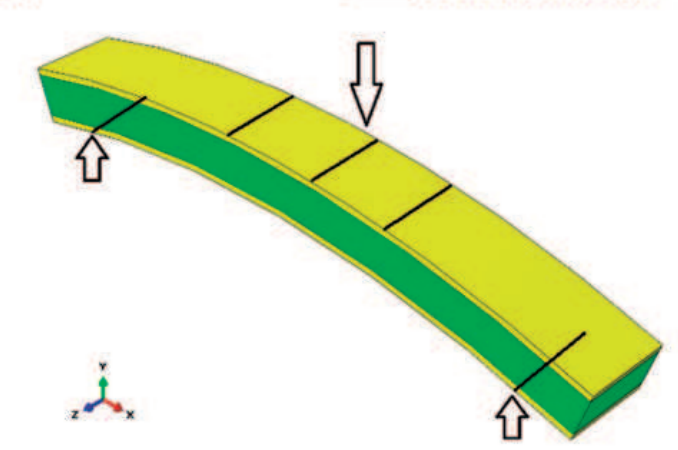

(b)

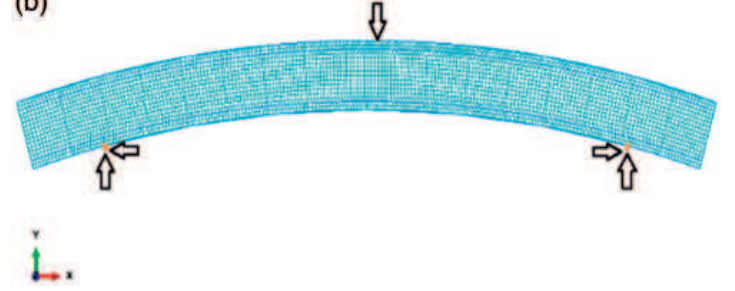

Figure 18. The 3D geometric model with its boundary conditions (a) and mesh size (b) used into the numerical analysis of the flexural test.

the relative stiffness of sandwich materials. In fact, for some core materials, the core shear modulus is a function of the direction that the core is oriented relative to the length of the specimen. Final cracking was observed on the skin in contact with the supports which drive the load, as shown in Figure 17. It is mainly its resistance to compression which is the most important factor after rupture of the core. Specific geometric factors that affect sandwich facing stiffness and thereby the sandwich flexural stiffness include facing thickness, core cell geometry, and facing surface flatness (toolside or bagside surface in compression).

Then, a comparative study between the experimental and numerical results has been carried out, taking into account the various important parameters of the geometry of the material and the associated mechanical characteristics of the data sheets. It can be seen from the table below that the damage modes are predicted in the associated numerical models depending strongly on the type of test and the nature of the material being studied. Figure 18 shows the numerical model used to simulate

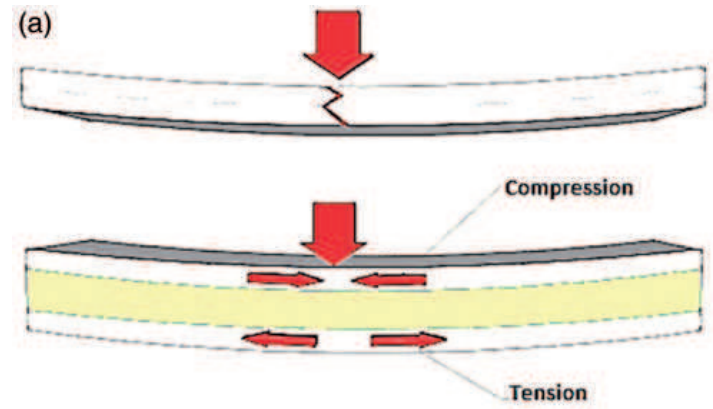

(b)

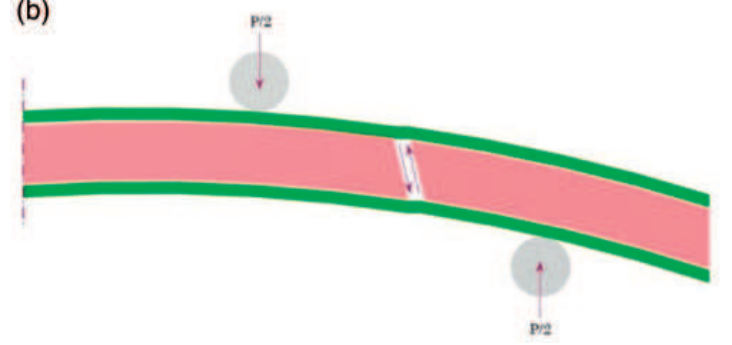

Figure 19. Most observed damage failures in sandwich structures under applied bending load. (a) Tension/compression strains on the skins; (b) damage shear cracking into sandwich cores.

the three- and four-point static bending tests of the composite sandwich. The loading and the support conditions in specimens are simulated in the finite element analysis by line loads. For reasons of simplification of the model, the structure is assumed to be a rigid body between steel rollers, curved foam and the two skins (Figure 18). When simple rollers simulate the loading and the support conditions, the stress and displacements fields near the region of the applied load are not affected in case that a static finite element analysis is applied to the sandwich beam without considering contact analysis. ${ }^{35}$ On the other hand, contact analysis must be applied between the cylinders and the sandwich beam, which is out of the scope of this study. As shown in Figure 18(a), the displacement is applied to lines belonging to the partitioned faces and therefore no contact technique is used to further simplify the model. Another point that has been checked is the mesh size. In fact, the variation of this parameter has little effect on the numerical results because of the linear displacement that has been imposed in the model and the simplicity of the geometry which allowed a rapid computational time.

Based on numerical simulations, the principle mechanisms of failure initiation into specimens under three-point and four-point bending tests are shown in Figure 19. They were studied numerically based on experimental results. The FE analysis results, which concerns just the elastic linear behavior, showed a good agreement with the elastic experimental results. Using the maximum deflection value as an input in 
Table 3. Experimental and predicted maximum elastic load of the composite sandwich structures under flexural bending.

\begin{tabular}{|c|c|c|c|c|}
\hline \multirow[b]{2}{*}{ Specimen type with: } & \multirow[b]{2}{*}{$\begin{array}{l}\text { Experimental } \\
\text { failure load }(\mathrm{kN})\end{array}$} & \multicolumn{3}{|c|}{ Theoretical failure load (kN) } \\
\hline & & $\begin{array}{l}\text { Shear failure of } \\
\text { the core }\end{array}$ & $\begin{array}{l}\text { Shear failure of } \\
\text { the core }{ }^{b}\end{array}$ & $\begin{array}{l}\text { Compressive failure } \\
\text { of the } \operatorname{skin}^{c}\end{array}$ \\
\hline Gridded PET foam 70 (+ Res) & 2605 & 2500 & 2495 & 4354 \\
\hline Gridded PET foam 70 (- Res) & 2458 & 2349 & 2345 & 3971 \\
\hline Standard PET foam 70 & 2590 & 2385 & 2381 & 3754 \\
\hline Standard PET foam 100 & 3317 & 2984 & 2976 & $46 I I$ \\
\hline Standard PET foam I50 & 6128 & 5608 & 5574 & 8403 \\
\hline Standard PET foam 200 & 7,801 & 7,390 & 7,335 & 10,432 \\
\hline PP Honeycomb foam 65 & 2,333 & 2,093 & 2,090 & 3,491 \\
\hline PU foam 29 with 3D glass bridges & 1,424 & 1,330 & $\mathrm{I}, 328$ & 1,359 \\
\hline
\end{tabular}

${ }^{\mathrm{a} C}$ alculated using equation (II).

${ }^{\mathrm{b}}$ Calculated using equation (12).

${ }^{\mathrm{c} C a l c u l a t e d}$ using equation (7).

Table 4. Experimental and numerical characteristics of each foam and corresponding skins of sandwiches under flexural bending.

\begin{tabular}{|c|c|c|c|c|c|c|c|}
\hline \multirow[b]{2}{*}{ Specimen type with: } & \multicolumn{3}{|c|}{$\begin{array}{l}\text { Shear strength of } \\
\text { the core }(\mathrm{MPa})\end{array}$} & \multicolumn{2}{|c|}{$\begin{array}{l}\text { Longitudinal strain } \\
\text { of the core }(\%)\end{array}$} & \multicolumn{2}{|c|}{$\begin{array}{l}\text { Compressive strength } \\
\text { of the skin }(\mathrm{MPa})\end{array}$} \\
\hline & $\begin{array}{l}\text { Technical } \\
\text { datasheet }\end{array}$ & $\begin{array}{l}\text { Experimental } \\
\text { result }^{\mathrm{a}}\end{array}$ & $\begin{array}{l}\text { Numerical } \\
\text { result }\end{array}$ & $\begin{array}{l}\text { Technical } \\
\text { datasheet }\end{array}$ & $\begin{array}{l}\text { Numerical } \\
\text { result }\end{array}$ & $\begin{array}{l}\text { Laminate } \\
\text { theory }\end{array}$ & $\begin{array}{l}\text { Numerical } \\
\text { result }\end{array}$ \\
\hline Gridded PET foam 70 (+ Res) & 0.50 & 0.76 & 0.95 & $15 \%$ & $0.4 \%$ & 376 & 90 \\
\hline Gridded PET foam 70 (- Res) & 0.50 & $0.7 \mathrm{I}$ & 0.61 & $15 \%$ & $0.9 \%$ & 376 & 312 \\
\hline Standard PET foam 70 & 0.50 & 0.72 & 0.64 & $15 \%$ & $1.2 \%$ & 376 & 327 \\
\hline Standard PET foam 100 & 0.75 & 0.90 & 0.80 & $10 \%$ & $0.9 \%$ & 376 & 288 \\
\hline Standard PET foam I50 & 1.40 & 1.70 & 1.66 & $7 \%$ & $0.7 \%$ & 376 & 352 \\
\hline Standard PET foam 200 & 1.80 & 2.24 & 2.17 & $5 \%$ & $0.6 \%$ & 376 & 353 \\
\hline PP Honeycomb foam 65 & 0.40 & 0.63 & 0.60 & $20 \%$ & $1.1 \%$ & 376 & 221 \\
\hline $\begin{array}{l}\text { PU foam } 29 \text { with 3D } \\
\text { glass bridges }\end{array}$ & 0.30 & 0.40 & 0.37 & $35 \%$ & $1.5 \%$ & 376 & 195 \\
\hline
\end{tabular}

${ }^{\mathrm{a}}$ Calculated using equation (10).

the model, which corresponds to the maximum critical constraint limit obtained experimentally (point from which either the skin or the core begin to fail), the FE analysis was successful in prediction of the maximum elastic constraints for all studied structures with the corresponding localization into each specimen. In fact, the shear failure of the different constituent cores in the constant shear force region occurred at different loads (Table 3) depending on mechanical properties of each studied core material (Figure 19(a) and (b)), associated with a skin-core debonding where the maximum traction damage initiation is reached. It was demonstrated in Table 4 that the foam core failed before the skin as noticed in the experimental tests. Also, to confirm this ascertainment, the compressive stress (S22) of the skin has been monitored up to the maximum elastic limit. It has been observed that the compressive stress does not reach the critical value at the top skin (Table 4) which means that the skin still sustains compressive load while the core is already failed (Figure 19(e) to (f)). Moreover, the longitudinal strain (LE11) concerning each core material shows a minor value compared to the ultimate tensile strain obtained from materials' datasheets, which indicates that the tensile failure of the core does not occur (Figure 19(c) and (d)). It should be noted likewise that there is some variability in sandwich specimens cracking, and that the arithmetic mean of each result was used as a reference.

To summarize, the different failure initiation modes that were observed experimentally are mainly caused by 


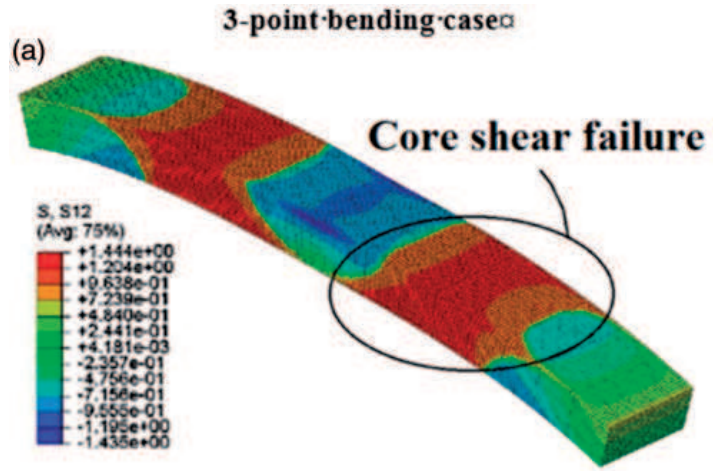

(c)

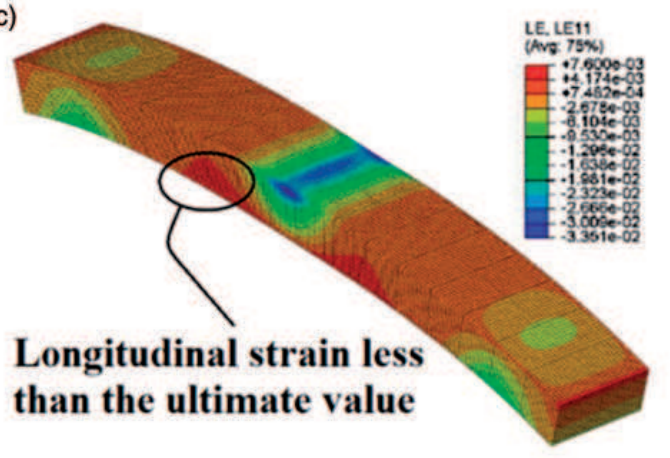

(e)

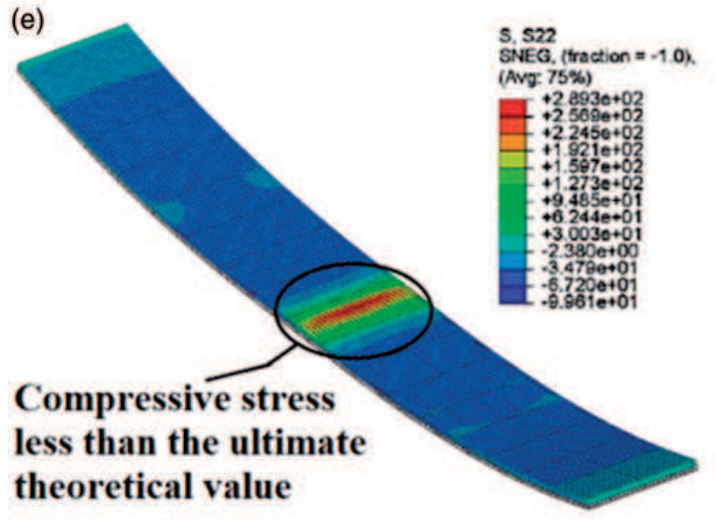

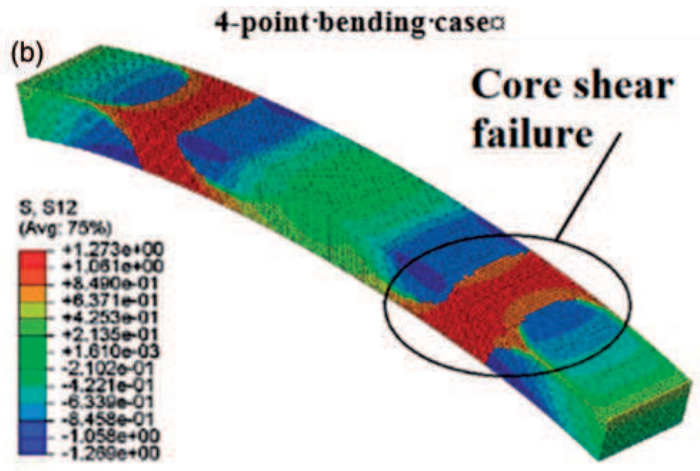

(d)
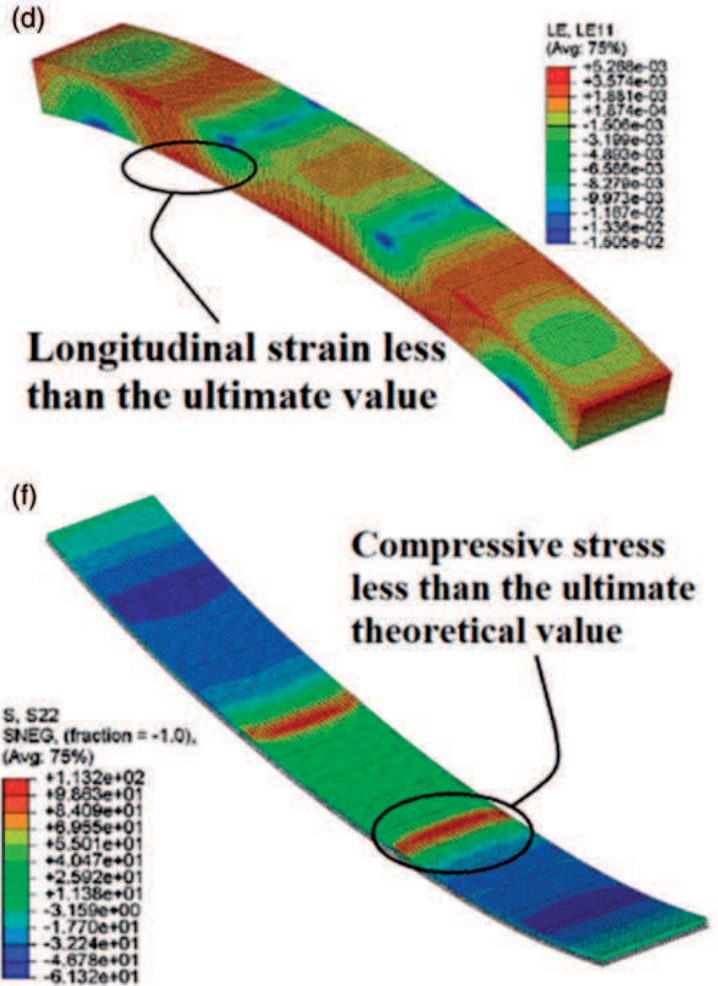

Figure 20. Principle mechanisms of failure initiation into specimens under bending tests based on numerical simulations: (a, b) inplane shear stress (SI2), (c, d) longitudinal strain (LII) and (e, f) compressive stress (S22).

the densities variability of the studied cores and by the bending configuration (three or four-point bending). Indeed, it is primarily the constituent core that is loaded in shear, from where we observe the appearance of the initial shear failure mode. For most test cases, the structure is loaded in both tension/compression of the upper and lower skins as described in Figure 20(a), and shear of the core that causes a random structure break (Figure 20(b)) in terms of damage location. In some cases, there has been a break of the core-skin interface which shows that this element must be optimized during the filament winding process, by increasing the polymerization time and the applied tension on the fibers during fabrication.
The prediction equations in the Theoretical and experimental evaluation of the flexural response section were used to determine the maximum load and the governing initial failure for the composite sandwich structures. The dominant initial failure mode was predicted to be core shear (Figure 20(b)). The estimated maximum load due to core shear failure and compressive failure of the skin was also calculated. Table 3 shows the theoretical failure load and the maximum load of the sandwich specimens based on experimental investigations. The theoretical load of shear failure predicted using equations (11) and (12) is between $4 \%$ and $12 \%$ lower than the actual failure initiation load. These results further show that the curved structures can 
better resist to bending stresses due to their geometry, and that the associated core shear failure load cannot be predicted by using the theoretical analysis, generally used for flat structures. The difference between the predicted and the actual failure load could be due also to the combined effect of the flexural stresses on the sandwich specimens resulting in a slightly higher failure load and the constituent materials non-linearity as well. In general, it has been demonstrated that the failure load of the composite sandwich structures can be reasonably predicted using the mechanical properties of each constituent material established from coupon tests. Similarly, the results indicated that the failure mode of the composite sandwich specimens tested in this study depends largely on the shear strength of the foam core and compressive strength of the composite skins.

Using the materials linear behavior determined from the coupon tests, the FE model has provided results in good agreement with the experiments. On the contrary, the theoretical result underestimated the failure initiation load with a good match on the experimental curve only in the initial slope. However, when increasing the applied load up to failure, a high divergence between the experimental and theoretical response was observed which attributed to the assumption of linear elastic behavior of the constituent materials that does not agree with their actual responses. In order of that, another analytical approach using the actual experimental stress-strain curves of all materials will be considered in the future publications to overcome the accuracy issue.

It was observed that three distinct damage events have taken place, respectively, before the final specimen failure which is facing break. Damage event- 1 was the crack initiation and propagation on the compression side just below the top face sheet-core interface. It was noticed that this delamination crack was never at the core-skin interface but about $1-1.5 \mathrm{~mm}$ below the interface. After several examinations, it was revealed that the resin penetrated/soaked into the core material by this depth as illustrated in Figure 21. It was observed that the crack always initiated at the sub-interface created by the resin-soaked, and the dry cells below the actual core-skin interface. This crack runs parallel to the beam axis from the point of initiation towards the end support, as shown in Figure 22. Damage event-1 occupied about $55 \%$ of whole test time.

Damage event-2 was the core shear initiation. The propagated crack in event-1 kinks at a certain distance depending on the load level, and shears through the core thickness, as shown in Figure 23. The crack reaches the bottom skin-core interface at the end of this event. Damage event-3 is the continuation of the previous event. As shown in Figure 24, it follows the

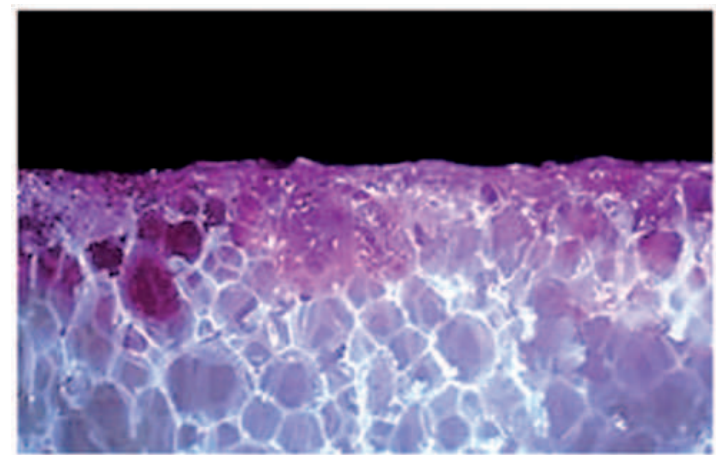

Figure 2l. Illustration of the resin uptake in a PET foam core.

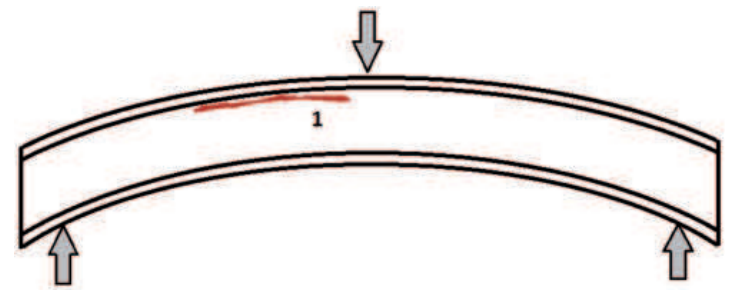

Figure 22. Damage event I.

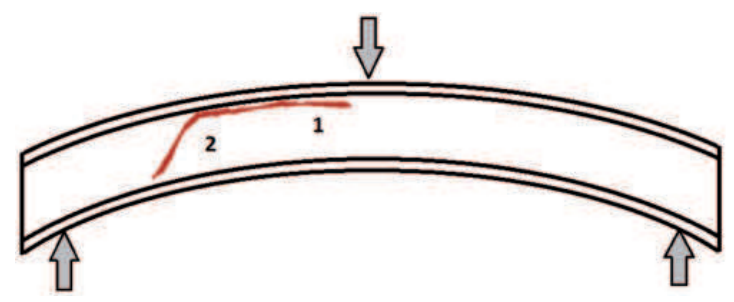

Figure 23. Damage event 2.

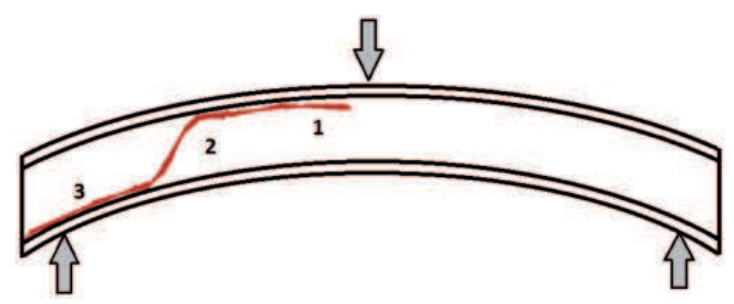

Figure 24. Damage event 3.

core shear and consists of delamination at bottom face/ core interface causing the separation of the core from the face-sheet. As the core shear propagates at a faster rate, the energy at the crack tip is sufficiently high to crisscross through the sub-interface and it reaches the much stiffer face sheet where it gets deflected along the core-skin interface. This is the reason why the delamination during damage event- 3 is not at the sub-interface, rather it is along the core-skin interface. 


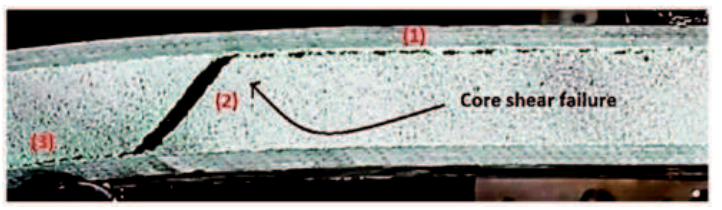

Figure 25. Typical final break on sandwiches with PET foams.

The final damage event is also a rapid event and occupies the remaining $7-8 \%$ of test time before final big crack. Finally, the specimen ultimately fails after this event and it is only the skins that must totally resist to loading until their damage initiation. The principle failure mechanisms of all specimens are shown in Figure 19. All damage events 1, 2 and 3 are predicted numerically. It can be observed that the crack in damage event- 1 initiates at the sub-interface whereas for damage events-3, the delamination takes place at the face-core interface separating the core from the face-sheet (Figure 25).

\section{Damage mechanisms identification by $A E$ data processing}

With Acoustic Emission, you can "listen" to the sounds of cracks growing, fibers breaking, and many other modes of active damage in stressed materials. In general, the $\mathrm{AE}$ technique was used to discriminate the different damage mechanisms from the detected AE signals in composite materials. A study of the main parameters extracted from AE signals is increasingly used to separate and identify the sources of different mechanisms. In this context, many studies ${ }^{36,37}$ were conducted on composite materials. The damage mechanisms of sandwich materials which are very complex composite materials (two skins and core) are less investigated. Moreover, there are a few studies on the non-destructive evaluation of sandwich materials by AE technique. For example, Quispitupa et al. ${ }^{38,39}$ investigated the damage modes in sandwich composites subjected to static loading.

In relation with our approach, a detailed study was carried out on skins laminates and sandwich specimens with PET, PU and PP foams using an AE real-time monitoring system in terms of amplitude and counts, especially when the mechanical behavior of the structure varies nonlinearly, and by linear location determination modes to detect longitudinally the damage in each tested specimen. In addition, the acoustic emission analysis allows us to understand the contribution of different types of damage to the non-linear behavior.

Amplitude and cumulative counts. The acoustic emission data was analyzed using two temporal parameters of the acoustic signals: amplitude and cumulative number of counts. After multiple initial trials, these parameters have proved to allow a good repeatability of the data processing, as illustrated in Figure 8. In this way, monitoring the amplitude of the acoustic emission signals collected at each step of damage gave the results presented hereafter. The corresponding value of force of the initial observed damage is associated with an important decrease of this force. This concept is better understood by the exploitation of acoustic emission results that shows an initial cumulative number of hits detected before the decrease of the force, in four-point bending (Figure 26(a) to (t)). Compared to non-destructive testing of sandwich structures in mechanical tests, the figures shown above clearly illustrate that an acoustic activity starts well before a sudden important decrease of the elastic force limit indicating a major damage.

More localized damage begins and progresses during loading to a level of instability that causes the sudden crack of the foam. Through the load-amplitude plots as a function of the test time for each step of damage exposed in Figure 26, we usually notice the existence of two distinct groups of acoustic emission signals with amplitudes varying between 50-60 dB (group A in light green color) and $90-100 \mathrm{~dB}$ (group B in purple color). So, based on the results found in the literature, ${ }^{40}$ the high amplitude signals correspond to fiber failure in the skin and/or local sandwich break in the foam, while those of low amplitudes are from different failures in the polymer matrix and fiber/matrix debonding in the skin. Especially for sandwiches with PET standard and gridded foams, it is noted during the tests that it always has the presence of the break mode in compression of the core comprising inter-laminar shear stress. In this case, the length of delamination was very great. This mode is illustrated mainly by the sudden increase in the curve slope of the cumulative number of hits. This is accompanied by the appearance of the amplitude ratio of more than $90 \mathrm{~dB}$, colored in light purple on the corresponding curves. In the other hand, materials with PP NIDA and PU cores are characterized by a quasi-linear increase in amplitudes and cumulative number of hits, due to the nature of the constituent materials, which have mainly undergone a break mode by a successive compression of the layers. For the composite material constituting the skins, a strong acoustic activity is detected in the tests because of the matrix-fiber interaction break in the material as well as the tensile rupture of the fibers of the lower face of the specimen as well as the compression of the upper face. Therefore, the study of AE signals collected during tests made it possible to identify four damage mechanisms: the core damage followed by resin cracking, interfacial debonding and fibers breaking. 
Sandwich with PET foam $70 \mathrm{Kg} / \mathrm{m}^{3}$ - Gridded (+ res) $h=33 \mathrm{~mm}$

Sandwich with PET foam $70 \mathrm{Kg} / \mathrm{m}^{3}$ - Gridded (- res) $h=33 \mathrm{~mm}$

Sandwich with PET foam $70 \mathrm{Kg} / \mathrm{m}^{3}$ - Standard $\mathrm{h}=33 \mathrm{~mm}$

Sandwich with PET foam $100 \mathrm{Kg} / \mathrm{m}^{3}$ - Standard $h=33 \mathrm{~mm}$

Sandwich with PET foam $150 \mathrm{Kg} / \mathrm{m}^{3}$ - Standard $\mathrm{h}=33 \mathrm{~mm}$

Sandwich with PET foam $200 \mathrm{Kg} / \mathrm{m}^{3}$ - Standard $\mathrm{h}=33 \mathrm{~mm}$

Sandwich with Nida PP foam $65 \mathrm{Kg} / \mathrm{m}^{3} \mathrm{~h}=33 \mathrm{~mm}$

Sandwich with PU foam $29 \mathrm{Kg} / \mathrm{m}^{3}$ with $3 D$ bridges $h=33 \mathrm{~mm}$

Laminate composite skin $h=8 \mathrm{~mm}$

Laminate composite skin $h=22 \mathrm{~mm}$

(a)

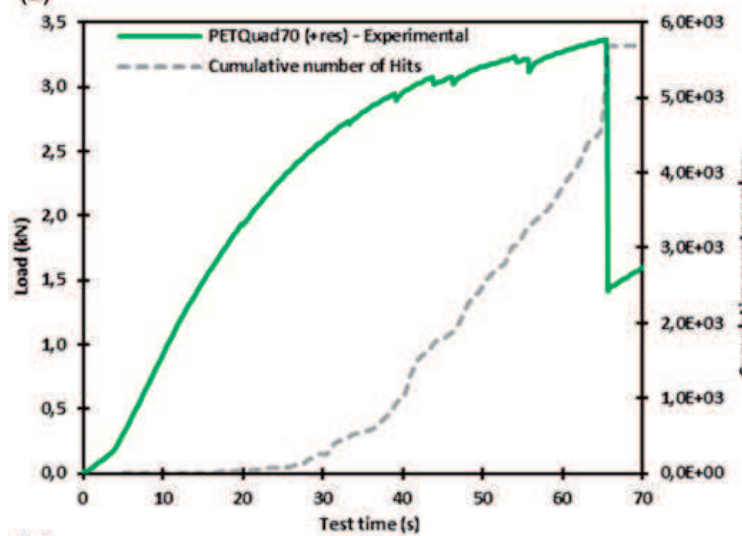

(c)

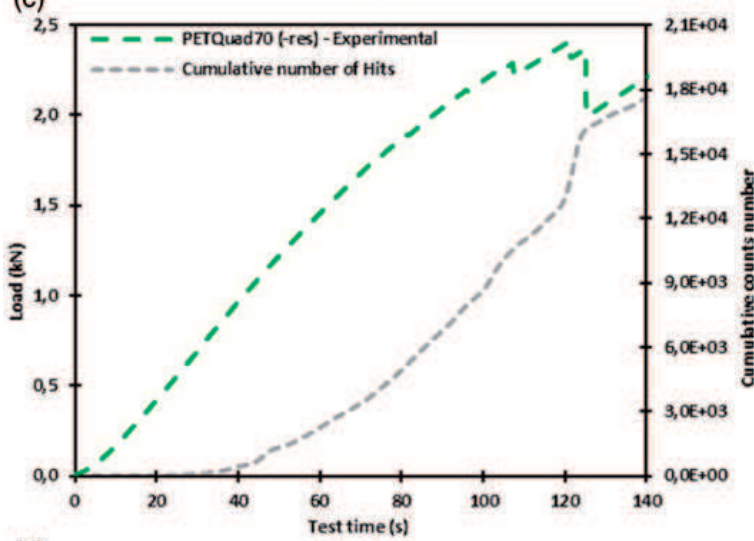

(e)

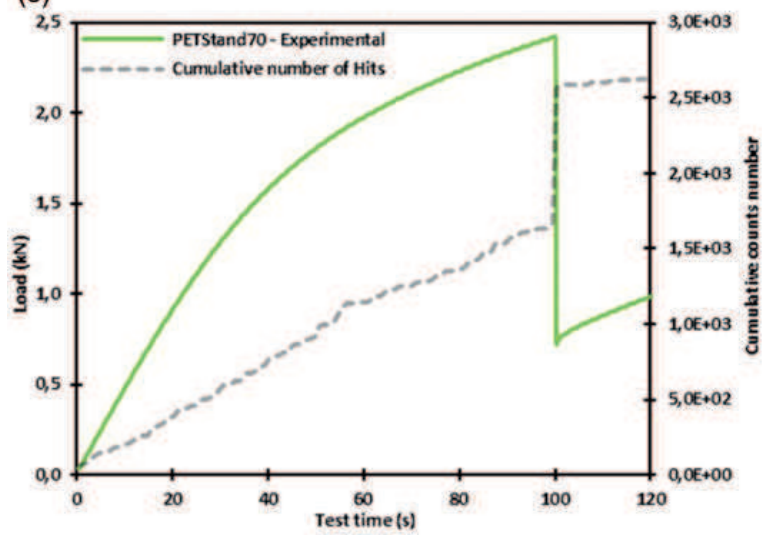

(b)

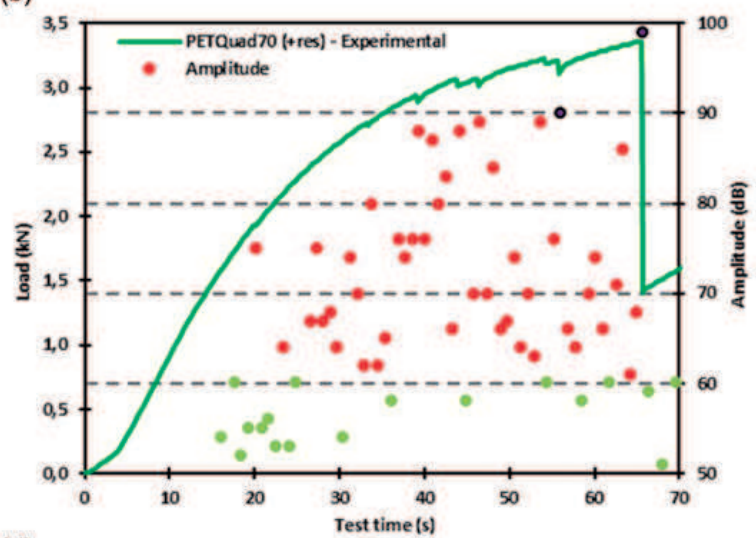

(d)

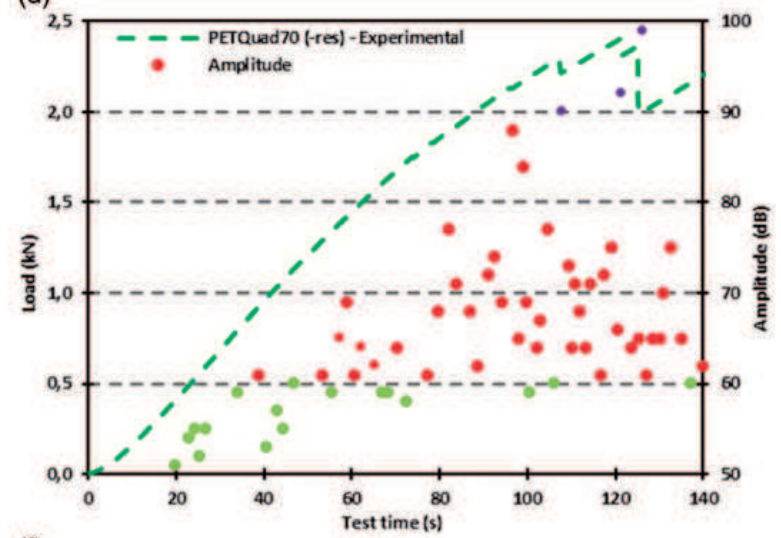

(f)

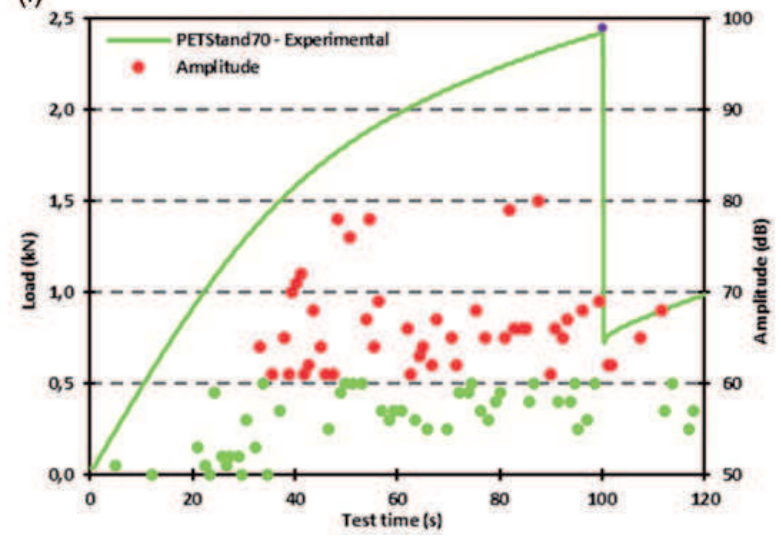

Figure 26. 4-point bending study of sandwich structures by acoustic emission - amplitudes. 

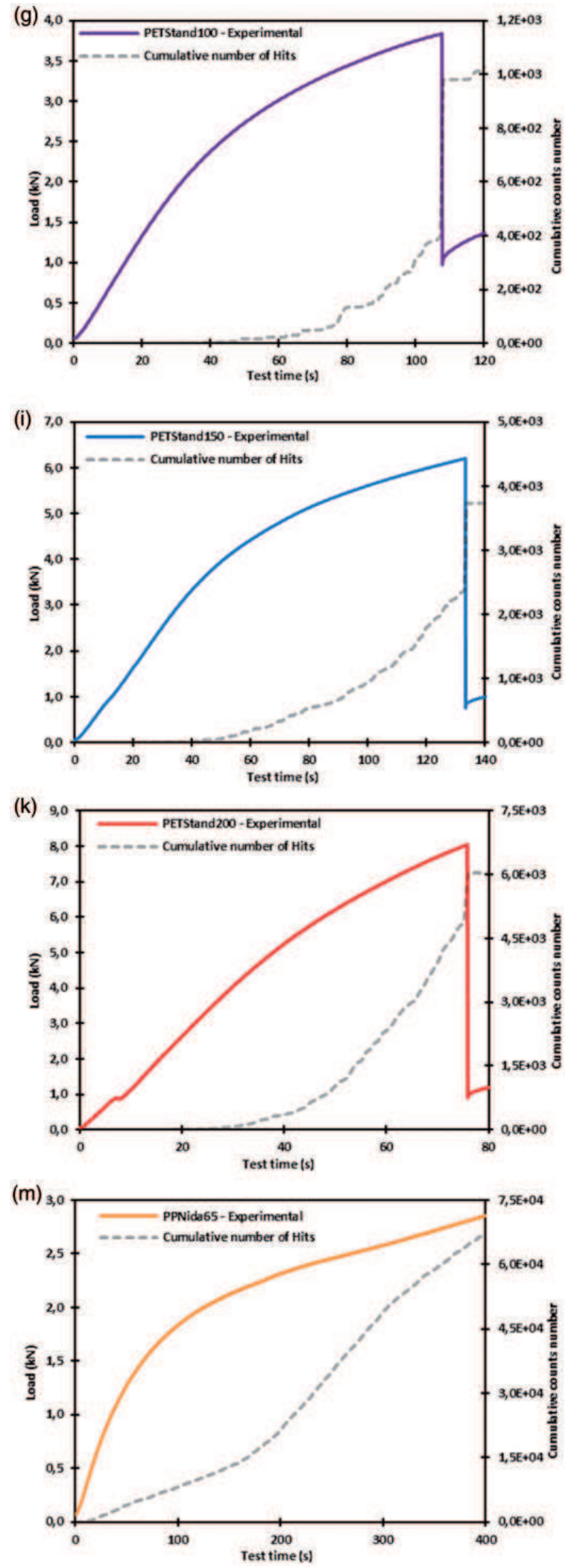

Figure 26. Continued.
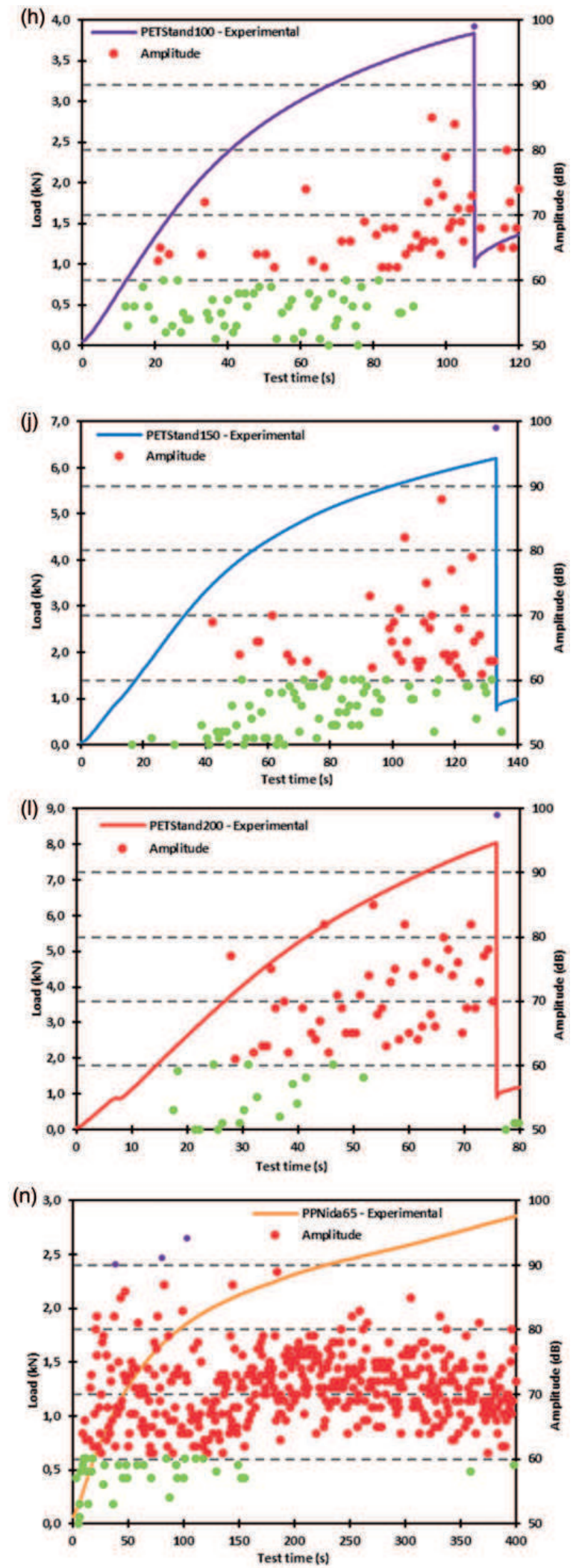

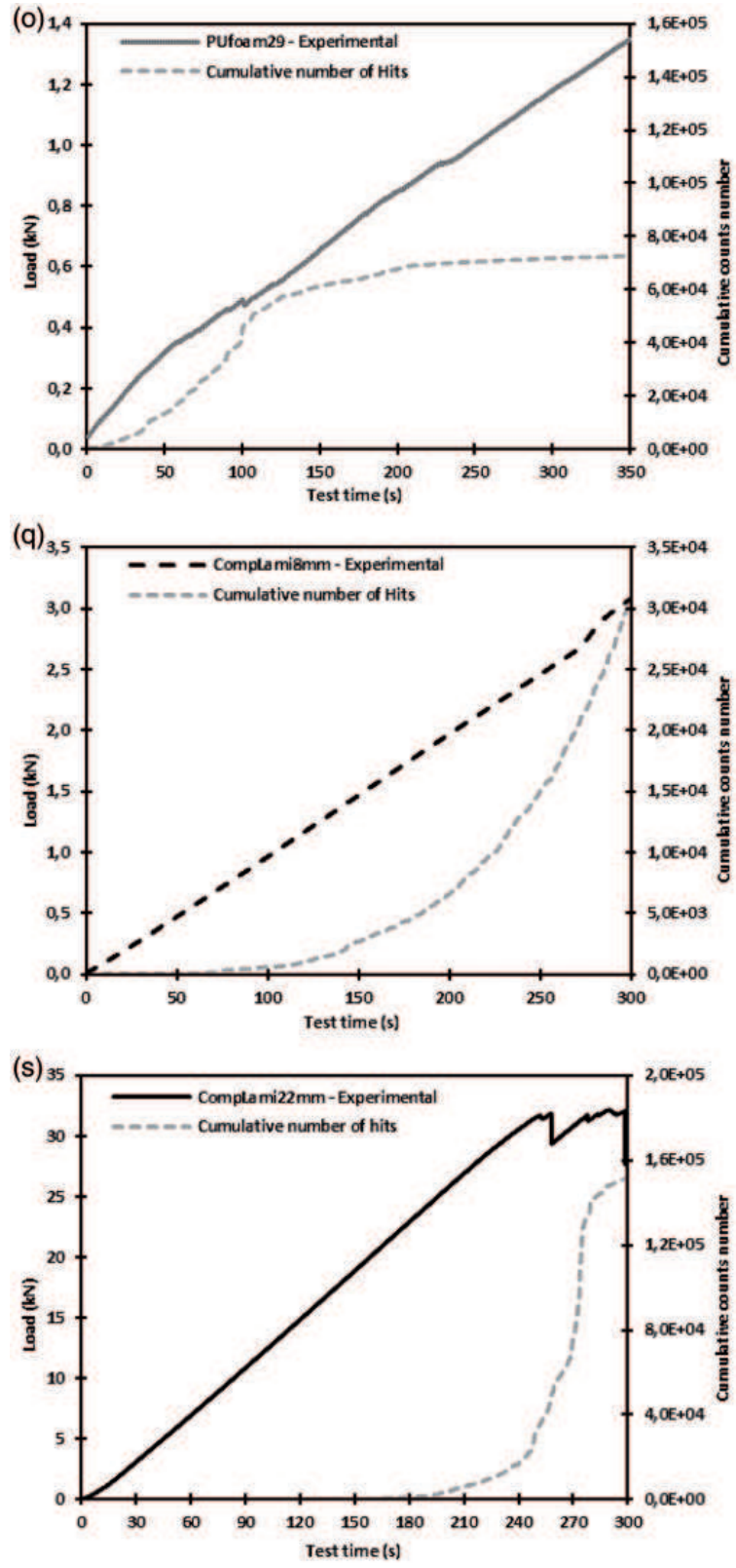

Figure 26. Continued.

AE figures represent dynamic, transient data that is updated continuously throughout the duration of the test. Care must be exercised in interpreting AE graphical presentations. What is significant is the cumulative AE activity during various time intervals as it forms the basis for life prediction modeling. Data shown in Figure 26 (Amplitude vs Time) provides an overall AE statistics during the time; for example, concerning PET standard or gridded foam types with different densities, we can see that the core damage activity occurred $70 \%$ of the time, whereas fiber breakage consumed only about $1-3 \%$ of the typical static testing time. The load increased linearly with time then a slight decrease in
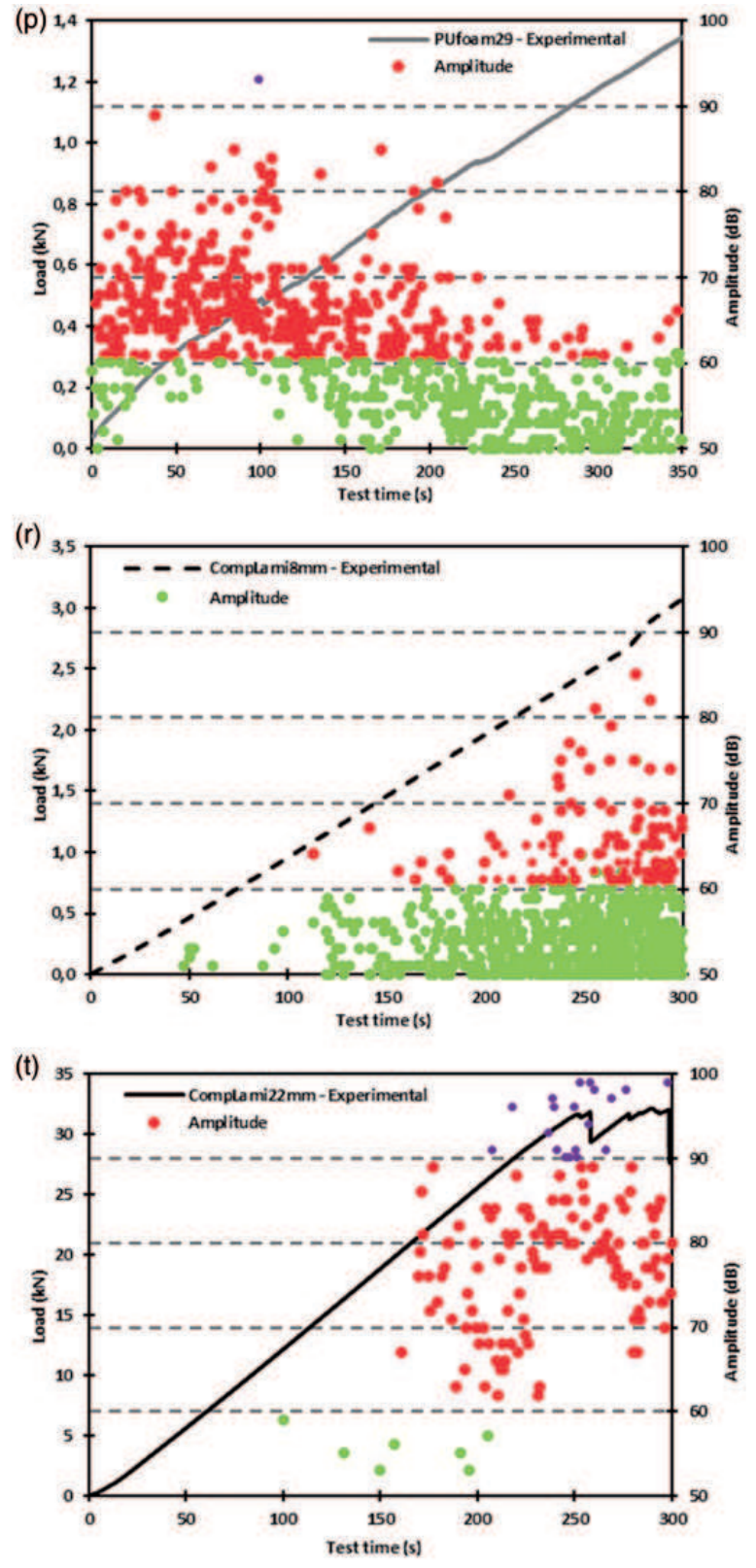

stiffness was observed due to the initiation of shear cracking of the core and the foam non-linear response as well. This point is confirmed by the increase of the cumulative number of hits that changes suddenly when an internal cracking is occurred inside the specimen. The sandwich then failed when the shear cracks propagate diagonally and extend to separate the skin from the core at the interfacial surface. The correlation between the experimental tests and the AE monitoring is verified by visual observation and captured videos.

Concerning the determination of the damage initiation, the noticeable increase in the amplitude value observed on all the curves at the beginning of the initial 


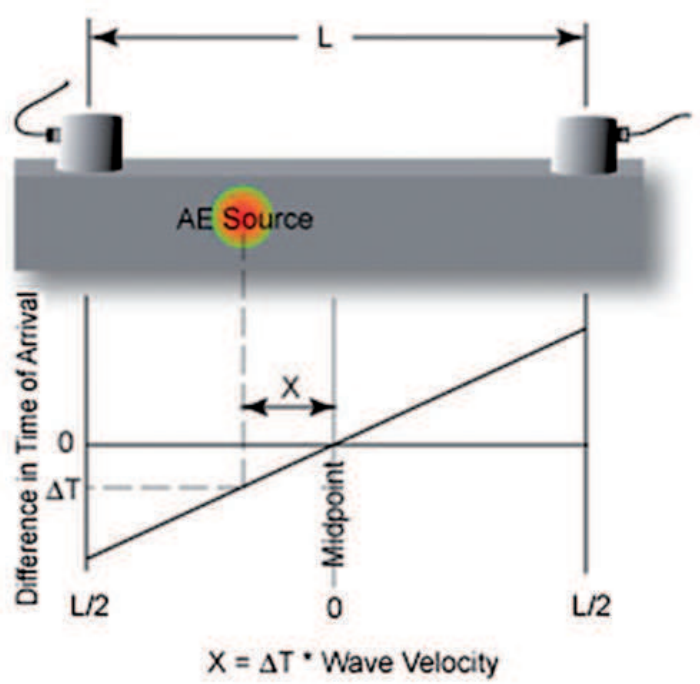

Figure 27. Linear location technique by acoustic emission.

linear part allows the verification of the beginning of the internal damage which generally occurs just at the end of the linearity. The increase in the number of hits also shows that there is an acoustic activity from the beginning of the bending test and that is correlated with the amplitude analysis and the visual observation of the tests. Especially for sandwich structures with PP Nida and PU cores, the graphs (n) and (p) in Figure 26 show a high activity of acoustic events from the beginning. This is due to the strong presence of the resin in the characteristic spacing into the PP Nida cores, and the innovative geometry of PU core with $3 \mathrm{D}$ glass bridges which contain the resin to reinforce the structure by connecting the two constituent facings.

Location events. In acoustic emission, the time of signals' arrival at each sensor is a function of the source location and the propagation speed of the acoustic waves. One of the commonly used computed-source location techniques is the linear location principle shown in Figure 27. When the source is located at the midpoint, the time of arrival difference for the wave at the two sensors is zero. If the source is closer to one of the sensors, a difference in arrival times is measured. To calculate the distance of the source location from the midpoint, the arrival time is multiplied by the wave velocity. Whether the location lies to the right or left of the midpoint is determined by which sensor first records the hit. This is a linear relationship and applies to any event sources between the sensors. Because the above scenario implicitly assumes that the source is on a line passing through the two sensors, it is only valid for a linear problem.

The location events issued from the acoustic emission signals, collected at each step of damage, gave the results presented hereafter (Figure 28(a) to (j)). These results confirm the previous analysis with numerical approach for damage localization. For sandwich structures with PET foams, whether the type is gridded or standard, the different observed failure modes are:

A. The local buckling of the upper skin that is observed for the three-point bending tests in most cases.

B. This local buckling is sometimes replaced by a shear failure of fibers in the upper skin that spreads by delamination between the skin and the foam.

C. For the three and four-point bending, we observe mainly a shear failure into the two types of PET foams propagating after a catastrophic delamination that occurs between the constituents of sandwich structure (skin-core interface).

For specimens with PP Nida and PU cores, a compressive behavior was observed throughout each type of core with a quasi-linear behavior. At the end, the two skins are tightened one against the other since the core material is completely crushed. However, the influence of the presence of the resin into gridded PET foams with a density of $70 \mathrm{~kg} / \mathrm{m}^{3}$ (Figure 28(a)) can be noticed. This made the acoustic activity to increase due to the progressive rupture of the resin during the quasistatic bending test, which is also explained by the presence of the grids and therefore the geometric discontinuity in the structural sandwich material. When these grids are less open as shown in Figure 28(b), we notice that the acoustic activity has decreased and the rupture has become more localized compared to the other case where the grids were more open, and therefore we had more resin absorption and a quasi-random fracture.

The sudden break occurs as a function of the density of the core in the studied sandwich structure. In fact, for sandwiches with standard PET foams ranging from 70 to $200 \mathrm{~kg} / \mathrm{m}^{3}$, the damage became more localized when the density increased due to having more closed cells and therefore a more solid material. For sandwiches with Nida PP foams and sandwiches with PU foams, damage is visible throughout the whole structure almost equally as well as for laminate composites of different thicknesses. This is due to the rigidity of the studied material and its several constituents which disperse the energy throughout the specimen.

According to AE analysis and results (such as Figure 26 and source location in Figure 28), damage was classified in various constituents of the sandwich composite as a function of AE amplitude, presented in Table 5. The level of AE amplitude was found independent of the specimen geometry or loading type for the sandwich composite used. To confirm AE damage 
(a)

Sandwich with PET foam $70 \mathrm{Kg} / \mathrm{m}^{3}-$ Gridded $(+$ res) $h=33 \mathrm{~mm}$
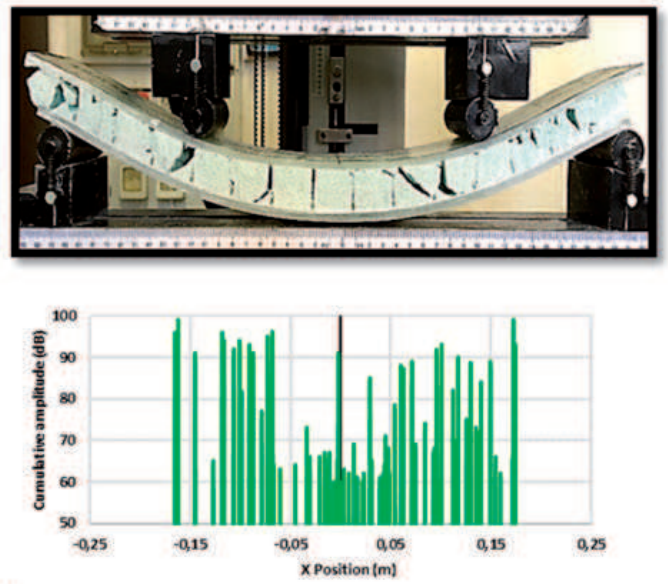

(c)

Sandwich with PET foam $70 \mathrm{Kg} / \mathrm{m}^{3}$ - Standard $h=33 \mathrm{~mm}$
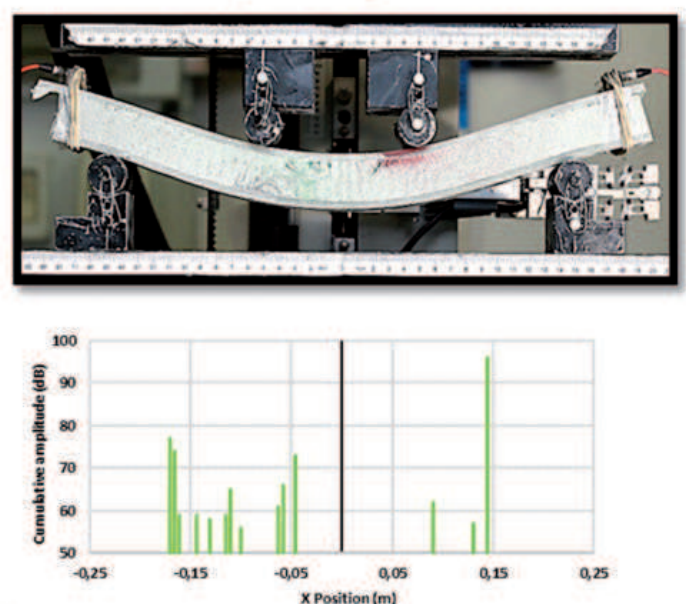

(e)

Sandwich with PET foam $150 \mathrm{Kg} / \mathrm{m}^{3}$ - Standard $h=33 \mathrm{~mm}$
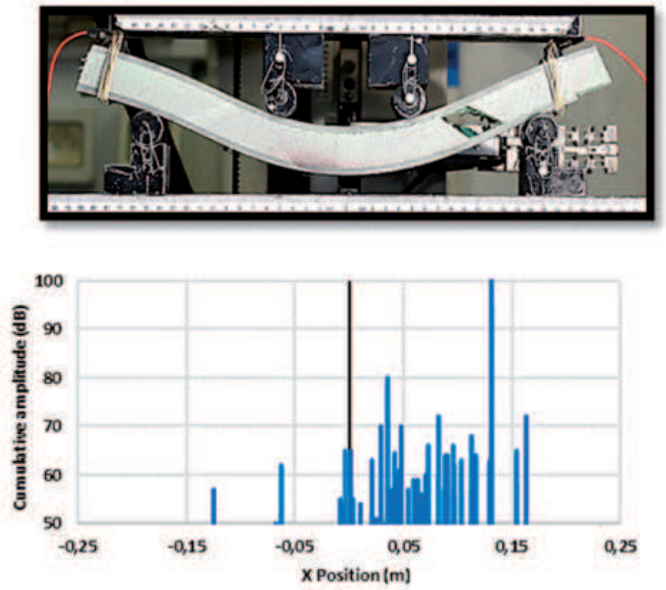

(b) Sandwich with PET foam $70 \mathrm{Kg} / \mathrm{m}^{3}$ - Gridded (-res) $h=33 \mathrm{~mm}$
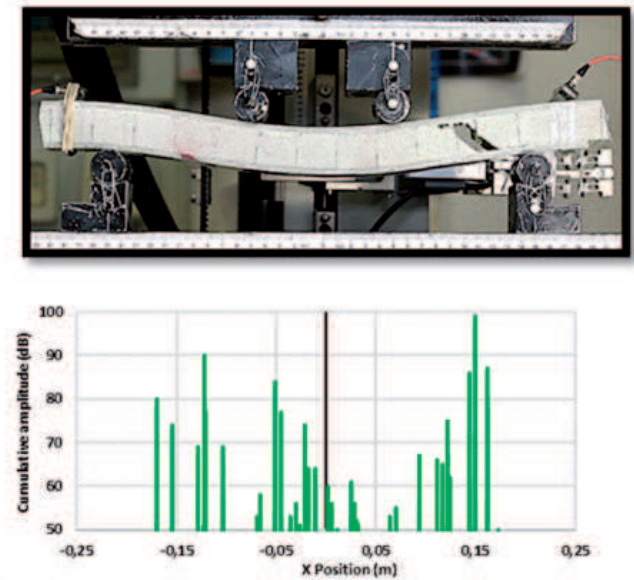

(d)

Sandwich with PET foam $100 \mathrm{Kg} / \mathrm{m}^{3}$ - Standard $h=33 \mathrm{~mm}$
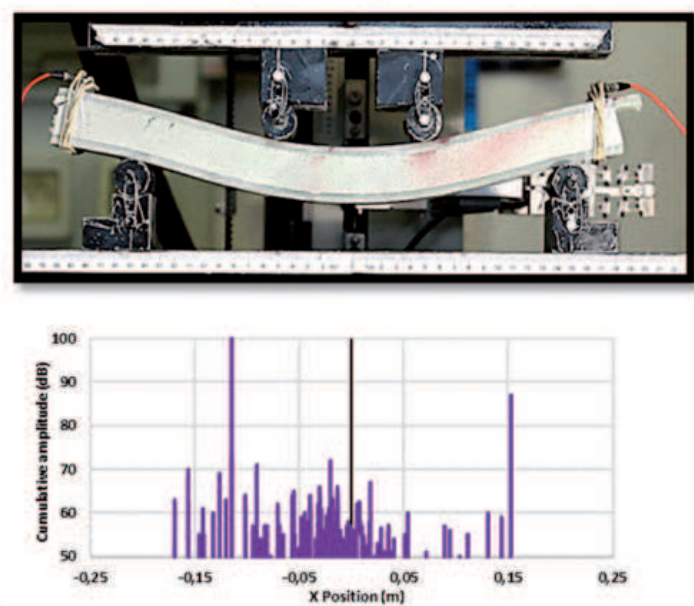

(f)

Sandwich with PET foam $200 \mathrm{Kg} / \mathrm{m}^{3}$ - Standard $h=33 \mathrm{~mm}$
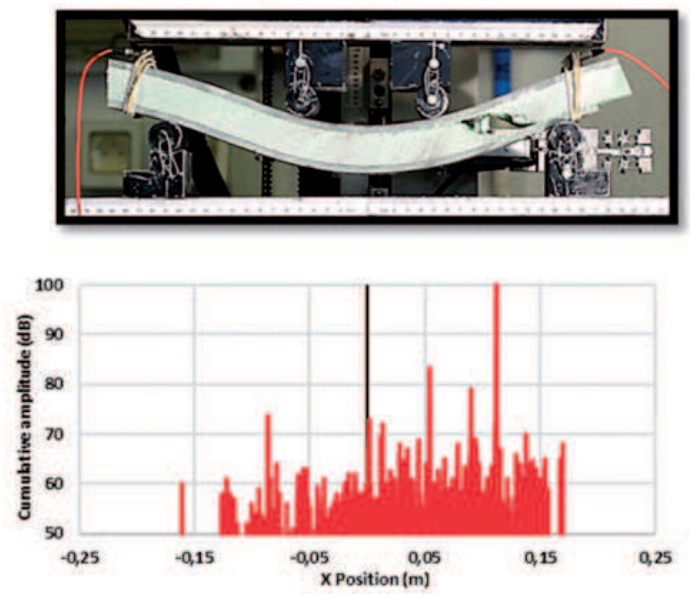

Figure 28. Four-point bending study of sandwich structures by acoustic emission - location events. 
(g) Sandwich with Nida PP foam $65 \mathrm{Kg} / \mathrm{m}^{3} h=33 \mathrm{~mm}$
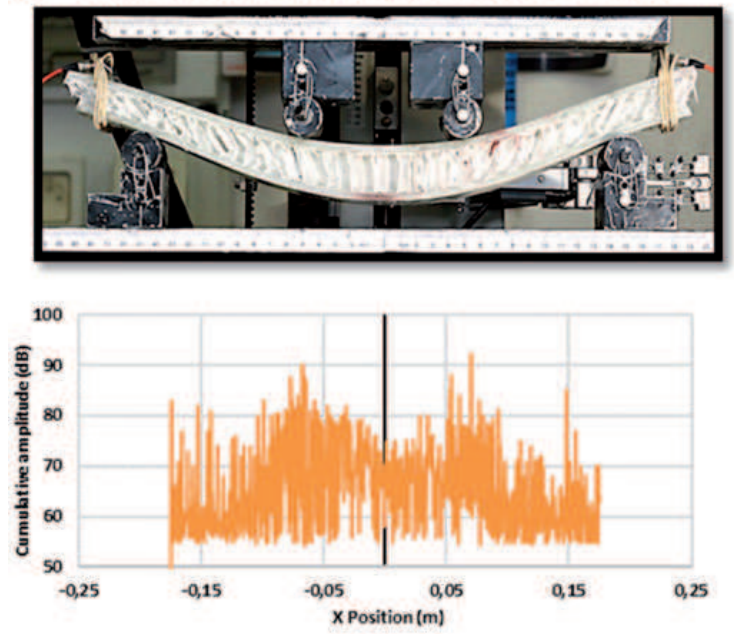

(i)
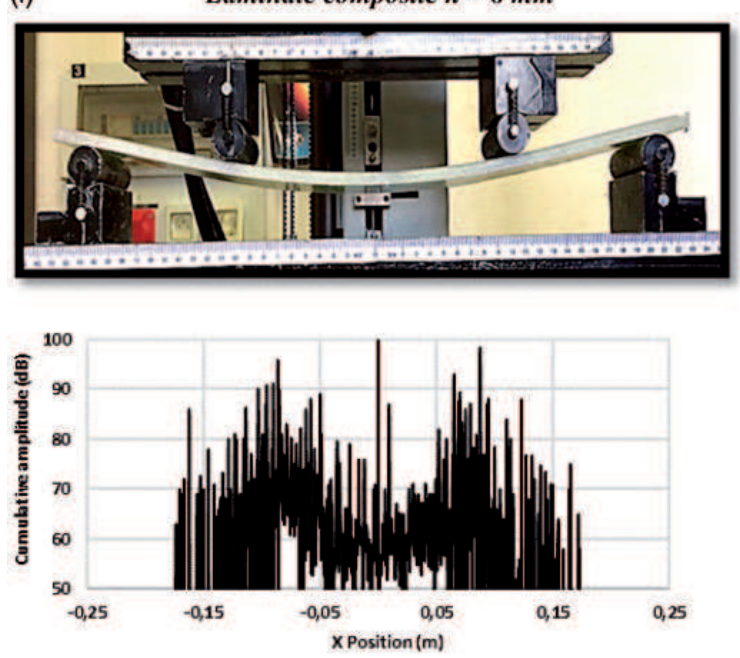

Figure 28. Continued.

classification results, various preliminary tests were terminated at certain AE amplitude and energy levels, and specimens were carefully removed, dissected and analyzed to confirm AE sequence of failure given in Table 5. The classification agreed well with the sequence reported in the literature, however, not necessarily with the amplitude or energy cutoffs, as AE parameters are quite sensitive to the material type. ${ }^{13,38,40}$

A high level of AE activity related to distinct crack initiation sites in the core and the interface near supports during the initial stages of the test was observed probably due to energy dispersion as a result of multiple crack initiation and propagation sites. Both opening and shearing modes were observed; however, sudden failure consistently occurred under the second mode (shearing). Substantial crack growth activity was observed in shearing rupture that propagated near the interface between the face-sheets and the core which led (h) Sandwich with PU foam $29 \mathrm{Kg} / \mathrm{m}^{3}$ with $3 D$ bridges $h=33 \mathrm{~mm}$
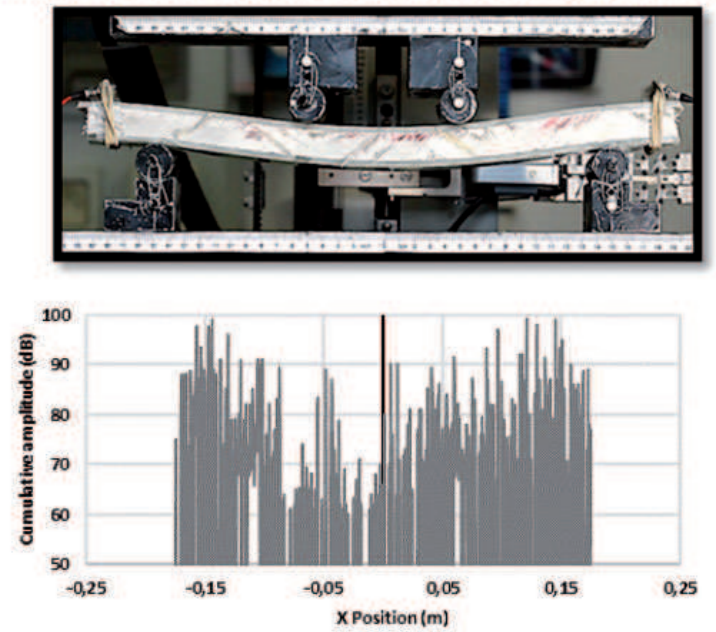

(j)
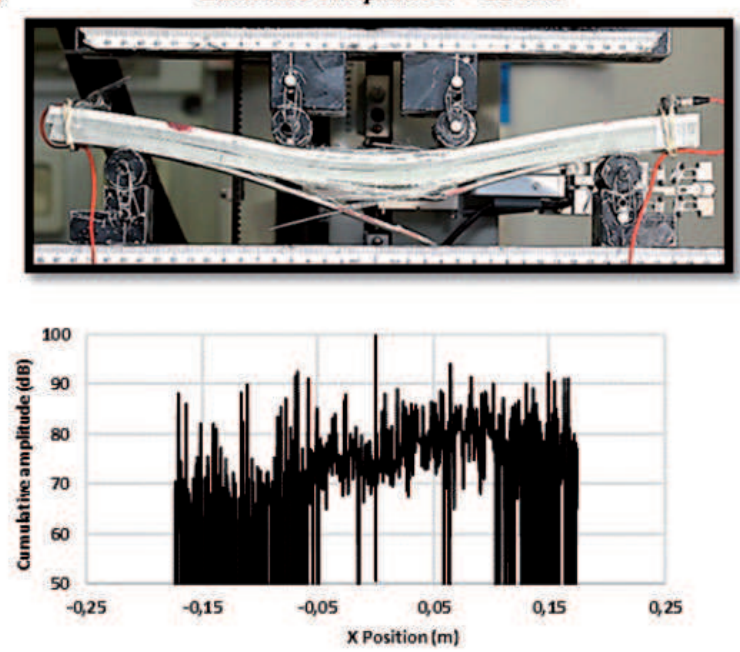

Table 5. Sequence of failure in sandwich composites with corresponding amplitude.

\begin{tabular}{ll}
\hline Failure mode & AE amplitude $(\mathrm{dB})$ \\
\hline Interface failure & $50-69$ \\
Core damage & $70-79$ \\
Resin cracking & $80-89$ \\
Fiber rupture & Above 90
\end{tabular}

to weakening of the two-phase action and subsequent cracking of the face-sheets (Table 5). Somewhat similar failure sequence has been reported in the literature ${ }^{21,22,27,28}$ for flexural tests on flat sandwich composites; however, unlike the reported results, significant fiber rupture never took place until sudden failure in the current study, as evidenced by AE analysis. 
AE activity tended to be high as the stress levels were enhanced. However, almost independent of the stress levels, AE analysis consistently indicated core crushing (localized within a $5 \mathrm{~mm}$ radial zone near the point of application of the load), core tearing and core shear failure near the interface with the face-sheets.

\section{Conclusion}

This paper deals with a complete mechanical characterization of PET, PU, PP foams/glass fiber composite sandwich structures by means of an extended theoretical, experimental and numerical analysis. Basically, the mechanical behavior of these structures was investigated under three- and four-point bending tests in conjunction with the Acoustic Emission technique (AE). The overall performance of sandwich structures depends clearly on the material properties of the constituents (facings, adhesive and core), geometric dimensions and type of loading. Sandwich beams under general bending, shear and in-plane loading display various failure modes. Failure modes and their initiation can be predicted by conducting a thorough stress analysis and applying appropriate failure criteria in the critical regions of the beam including threedimensional effects. This analysis is difficult because of the nonlinear and inelastic behavior of the constituent materials and the complex interactions of failure modes. For this reason, properly designed and carefully conducted experiments are important in elucidating the physical phenomena and helping the analysis. It must be emphasized that the key contribution of this paper is to distinguish the sandwich core having a good compromise concerning its mechanical behavior and which will subsequently be used in the manufacture of the final product that meets the needs of the industrial partners. A study of the main performance of the sandwich composites under investigation was depicted by considering multiple variables such as the material properties of the constituents, geometry and loading condition. The following conclusions could be drawn from the study. The experimental stress-strain curves showed an initial linear elastic behavior with a decrease in the slope prior to fracture. The specimens with PET foams with several densities failed due to shear failure of the core accompanied with skin-core delamination at the constant shear region. For specimens with PU and PP cores, there was mainly a quasi-static compression of the both types of cores since the corresponding material differs from that of PET foams. The theoretical analysis reasonably predicted bending stiffness of flat structures, but could not achieve good correlation with the behavior of curved ones. After this first study, the PET foam begins to show good performance compared to other candidate sandwich cores. As the mechanical behavior was described in detail, the FE predictions had good correlation with experimental results up to the elastic limit. To continue with, the results were presented by images of experimental configuration tests and corresponding plots of the distributions of the mechanical and acoustic parameters under study. The AE was used principally to confirm the correlation between damage mechanisms and acoustic emission classes. This study brought interesting considerations regarding the non-linear behavior of PET, PU and PP composite sandwich structures and how the first crack failure occurs for these different curved sandwich composites manufactured by the filament winding process. It should be emphasized that this manufacturing process has a significant influence on the mechanical properties of the core, especially for PET foams with/without grids, due to the presence of a certain quantity of absorbed resin or cast into the gaps, and can remain in foams depending on the nature of manufacturing. In fact, the inherent problem with the core-laminate interface consists on the consumption of this additional resin due to the porosity of the core surface or the cavities created during the forming process. Minimizing the resin consumption is a priority in any design to reduce weight and cost and therefore consideration of the formability and processing techniques are a critical part of the design process. However, the variability of observed results concerning the crack of the specimens is important. This is mainly due to local variations in the properties of each type of structure.

Finally, it is deduced that the PET core with an average density between 100 and $150 \mathrm{~kg} / \mathrm{m}^{3}$ is the best solution to be wound on a mandrel and thus to sustain the bending loads during the life cycle of the cylindrical tank. In terms of research and development, a variability approach seems to be essential to better understand the failure initiation of tested specimens. It is obvious from the conclusions that there is an emergent need towards the development of a theoretical model which could represent the curved materials and justify the nonlinear behavior, as well as the development of the numerical model to be able to investigate mechanical properties that cannot be determined experimentally.

\section{Declaration of Conflicting Interests}

The author(s) declared no potential conflicts of interest with respect to the research, authorship, and/or publication of this article.

\section{Funding}

The author(s) disclosed receipt of the following financial support for the research, authorship, and/or publication of this article: We thank the technicians of "Arts et Métiers ParisTech - CER Angers" who support all the projects of 
our research laboratory LAMPA and all our partners of FUI Project "SOLLICITERN" for their financial support and assistance during the study, particularly regarding the manufacture of the test specimens.

\section{Highlights}

- Design and study of a manufacturing process suited for curved sandwich structures.

- Experimental characterization and numerical evaluation of different sandwich types.

- A predictive model to get mechanical properties in elastic deformation is discussed.

- The acoustic emission monitoring leads to performance evaluation of materials.

- Influence of resin presence on sandwich stiffness made by filament winding.

\section{References}

1. Hull D and Clyne TW. An introduction to composite materials. Cambridge, UK: Cambridge University Press, 1996.

2. Kuenzi EW. Minimum weight structural sandwich. F.P.L., Madison: US Forest Service research note FPL-086, 1965.

3. Zenkert D. The handbook of sandwich construction. Engineering Materials Advisory Services, 1997. ISBN: 978-0-947817-96-1.

4. Berthelot JM. Composite materials, mechanical behavior and structural analysis, 3rd ed. Paris: TEC \& DOC, 1999.

5. Bannister D. An introduction to core materials: Part1 Designing sandwich structures. Materials Today Website, 2014.

6. ARMACELL Company Website - ArmaFORM PET foams, http://local.armacell.com/en/armaform-pet-foamcores/ (2017).

7. Hornsby PR. Thermoplastics structural foams: Part 2. Properties and applications. Mater Des 1982; 3: 443-455.

8. Thomsen OT. Theoretical and experimental investigation of local bending effects in sandwich plates. Compos Struct 1995; 30: 85-101.

9. Yoshii A. Optimum design of advanced sandwich composite using foam core. Adv Compos Mater 1992; 2: 289-305.

10. Triantafillou TC and Gibson LJ. Failure mode maps for foam core sandwich beams. Mater Sci Eng 1987; 95: 37-53.

11. Zenkert D. An introduction to sandwich constructions. London: Emas, 1995.

12. Gibson LJ and Ashby MF. Cellular solids: structure and properties, 2nd ed. Cambridge: Cambridge University Press, 1997.

13. Burman $\mathrm{M}$ and Battley M. Acoustic emission monitoring of foam core sandwich composites. J Sandwich Struct Mater 1999; 1: 147-175.

14. Refahi Oskouei A, Zucchelli A, Ahmadi M, et al. An integrated approach based on acoustic emission and mechanical information to evaluate the delamination fracture toughness at mode I in composite laminate. Mater Des 2011; 32: 1444-1455.

15. Daniel I, Gdoutos E, Wang K, et al. Failure modes of composite sandwich beams. Int J Damage Mech 2002; 11 : 309-334.

16. Andrews E and Moussa N. Failure mode maps for composite sandwich panels subjected to air blast loading. Int $J$ Impact Eng 2005; 36: 418.

17. ASTM Standard Test Method D7250 - 06. Determining sandwich beam flexural and shear stiffness. 2012.

18. ASTM Standard Test Method D790 - 10. Flexural properties of unreinforced and reinforced plastics and electrical insulating materials. 2010.

19. ASTM Standard Test Method C393 / C393M - 06. Core shear properties of sandwich constructions by beam flexure. 2006.

20. Nielsen A. Acoustic emission source based on pencil lead breaking. Danish Weld Inst 1980; 80: 15.

21. Craig A and Norman A. Collapse mechanisms of sandwich beams with composite faces and a foam core, loaded in three-point bending. Part I: analytical models and minimum weight design. Int $J$ Mech Sci 2004; 46: 561-580.

22. Manalo A, Aravinthan T and Karunasena W. Flexural behavior of glue-laminated fiber composite sandwich beams. Compos Struct 2010; 92: 2703-2711.

23. NF EN ISO 14125. Composites plastiques renforcés de fibres: Détermination des propriétés de flexion. 1998.

24. Lhuissier P and Laszczyk L. Caractérisation des structures sandwich, Techniques de l'ingénieur; Ref. M5815 V1, 2012).

25. Allen HG. Analysis and design of structural sandwich plates. New York, NY: Franklin Book Company, 1969.

26. Gibson RF. Principles of composite materials mechanics, 2nd ed. Leiden: CRC Press, 2007.

27. Russo A and Zuccarello B. Experimental and numerical evaluation of the mechanical behavior of GFRP sandwich panels. Compos Struct 2007; 81: 575-586.

28. Ramana Murthy PV and Rao KP. Analysis of curved laminated beams of bimodulus composite materials. J Compos Mater 1983; 17: 435-448.

29. Lo KH, Miyase A and Wang SS. Stiffness predictions for closed-cell PVC foams. J Compos Mater 2016; PG $002199831668302510.1177 / 0021998316683025$ [doi].

30. Salomi A, Greco A, Pacifico T, et al. Processing and properties of a polymer/composite double-layer laminate. Adv Polym Technol 2013; 32: E32-E43.

31. Greco A and Romano G. Selective reinforcement of LLDPE components produced by rotational molding with thermoplastic matrix pultruded profiles. Compos $B$ Eng 2014; 56: 157-162.

32. Bank LC. Composites for construction: structural design with FRP materials. Hoboken: Wiley, 2006.

33. Barbero EJ. Introduction to composite materials design. New York, NY: ASME, 1999.

34. DIAB. Sandwich concept. In: DIAB sandwich handbook, www.diabgroup.com (2016).

35. Kalogeras S. Study of the mechanical behavior of the short composite beam in flexure by the finite element method. 
Master Thesis, National Technical University of Athens, 2006.

36. El Guerjouma R, Baboux JC, Ducret D, et al. Nondestructive evaluation of damage and failure of fiber reinforced polymer composites using ultrasonic waves and acoustic emission. Adv Eng Mater 2001; 3: 601-608.

37. Marec A, Thomas JH and El Guerjouma R. Damage characterization of polymer-based composite materials: multivariable analysis and wavelet transform for clustering acoustic emission data. Mech Syst Signal Process 2008; 22: 1441-1464.
38. Quispitupa A and Shafiq B. Acoustic emission based tensile characteristics of sandwich composites. Compos $B$ Eng 2004; 35: 563-571.

39. Shafiq B and Quispitupa A. Fatigue characteristics of foam core sandwich composites. Int J Fatigue 2006; 28 : 96-102.

40. Berthelot JM. Matériaux composites, 5th edn, Paris: Lavoisier, 2012. ISBN: 978-2-7430-1450-6. 